\title{
A Safety and Licensing Roadmap to Identify the Research and Development Gaps of Commercial Molten Salt Reactors
}

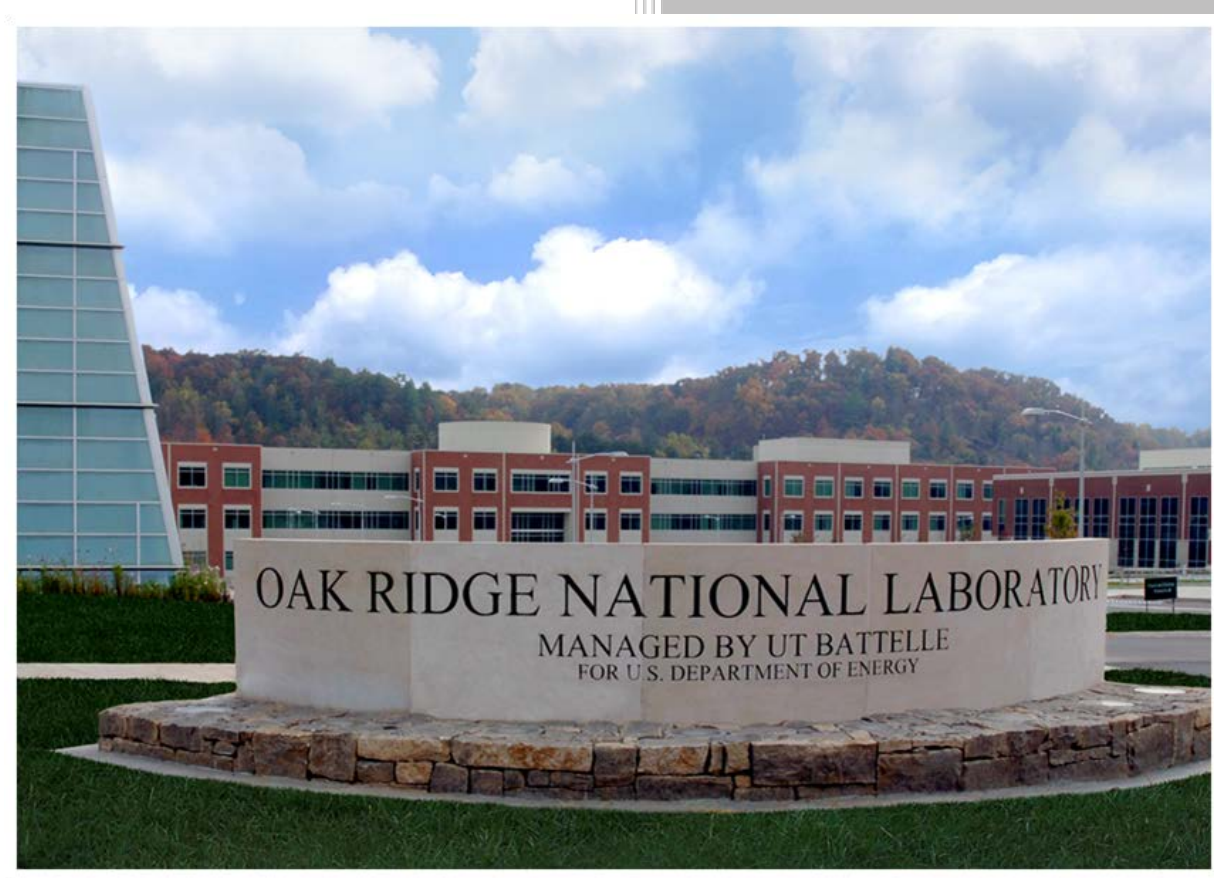
R. J. Belles
G. F. Flanagan
D. E. Holcomb
W. P. Poore

Approved for public release.

Distribution is unlimited.

September 2018 


\title{
DOCUMENT AVAILABILITY
}

Reports produced after January 1, 1996, are generally available free via US Department of Energy (DOE) SciTech Connect.

Website www.osti.gov

Reports produced before January 1, 1996, may be purchased by members of the public from the following source:

\author{
National Technical Information Service \\ 5285 Port Royal Road \\ Springfield, VA 22161 \\ Telephone 703-605-6000 (1-800-553-6847) \\ TDD 703-487-4639 \\ Fax 703-605-6900 \\ E-mail info@ntis.gov \\ Website http://classic.ntis.gov/
}

Reports are available to DOE employees, DOE contractors, Energy Technology Data Exchange representatives, and International Nuclear Information System representatives from the following source:

Office of Scientific and Technical Information

PO Box 62

Oak Ridge, TN 37831

Telephone 865-576-8401

Fax 865-576-5728

E-mail reports@osti.gov

Website http://www.osti.gov/contact.html

This report was prepared as an account of work sponsored by an agency of the United States Government. Neither the United States Government nor any agency thereof, nor any of their employees, makes any warranty, express or implied, or assumes any legal liability or responsibility for the accuracy, completeness, or usefulness of any information, apparatus, product, or process disclosed, or represents that its use would not infringe privately owned rights. Reference herein to any specific commercial product, process, or service by trade name, trademark, manufacturer, or otherwise, does not necessarily constitute or imply its endorsement, recommendation, or favoring by the United States Government or any agency thereof. The views and opinions of authors expressed herein do not necessarily state or reflect those of the United States Government or any agency thereof. 
Reactor and Nuclear Systems Division

\title{
A SAFETY AND LICENSING ROADMAP TO IDENTIFY THE RESEARCH AND DEVELOPMENT GAPS OF COMMERCIAL MOLTEN SALT REACTORS
}

\author{
Randy J. Belles \\ George F. Flanagan \\ David E. Holcomb \\ Willis P. Poore
}

Date: September 2018

\author{
Prepared by \\ OAK RIDGE NATIONAL LABORATORY \\ Oak Ridge, TN 37831-6283 \\ managed by \\ UT-BATTELLE, LLC \\ for the \\ US DEPARTMENT OF ENERGY \\ under contract DE-AC05-00OR22725
}





\section{CONTENTS}

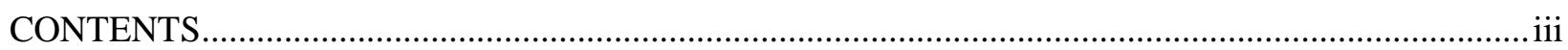

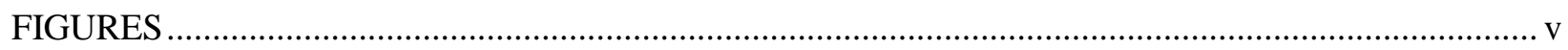

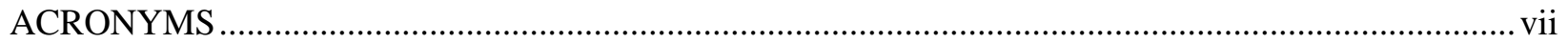

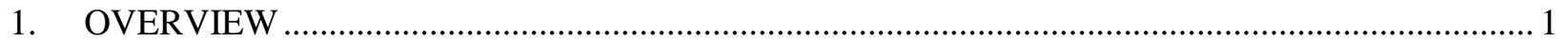

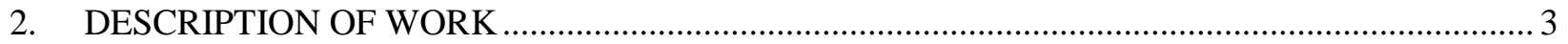

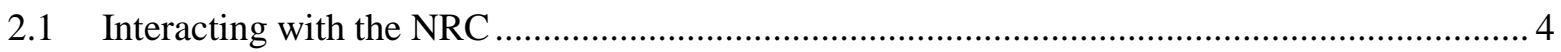

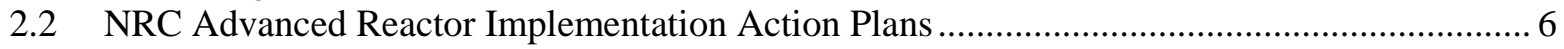

2.3 ORNL Statement on NRC Work and DOE Work …............................................................ 7

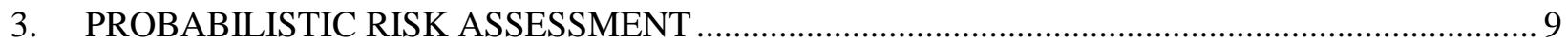

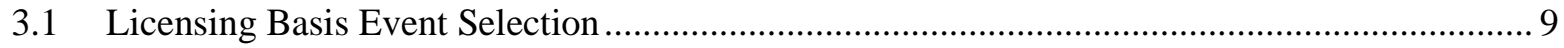

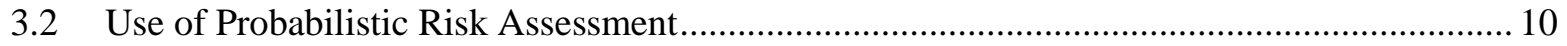

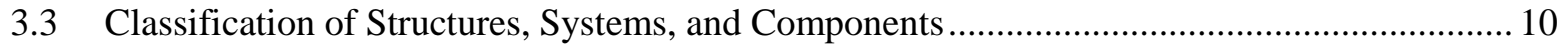

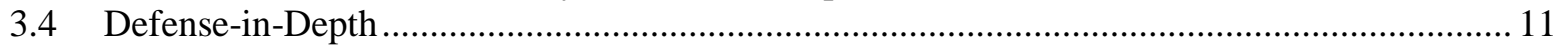

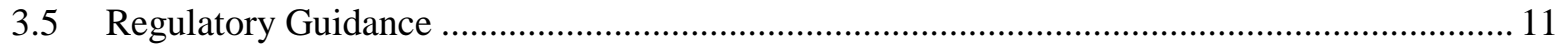

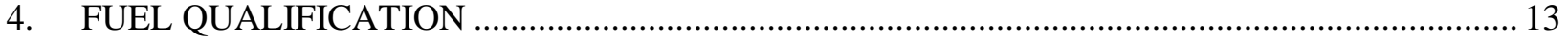

4.1 Demonstration of Liquid Fuel Performance …..................................................................... 13

4.2 Demonstration of FHR Fuel Performance ..................................................................... 15

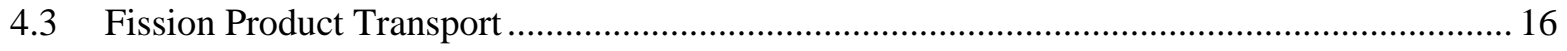

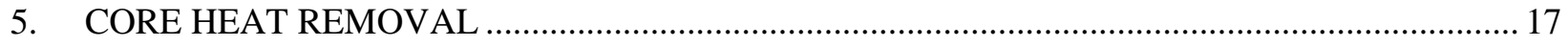

5.1 Codes for Physics and Thermal Fluids …......................................................................... 17

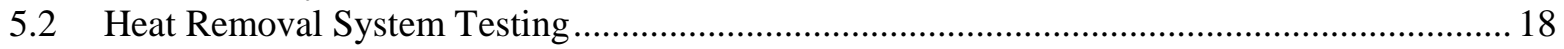

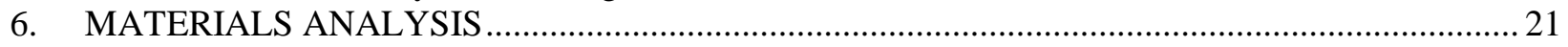

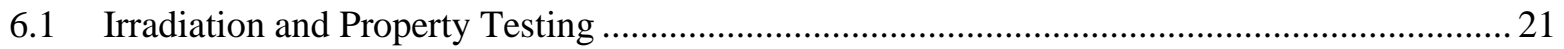

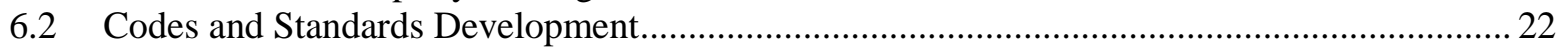

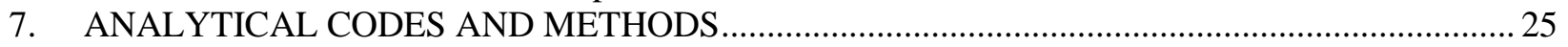

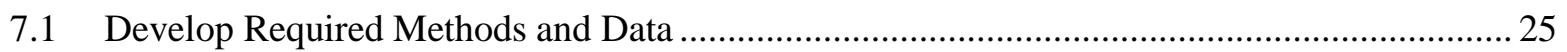

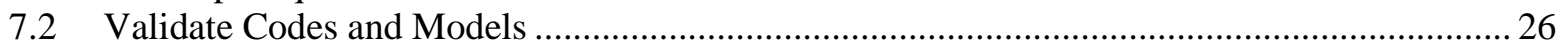

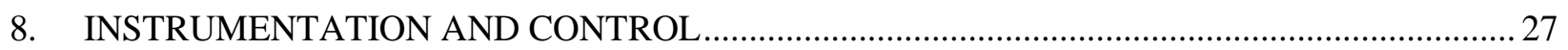

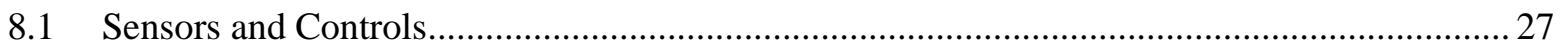

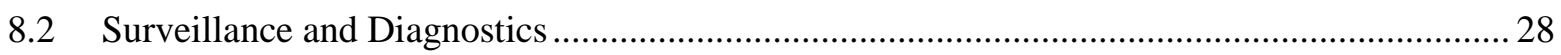

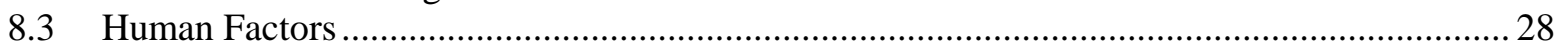

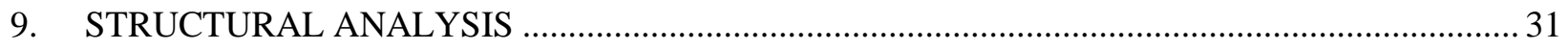

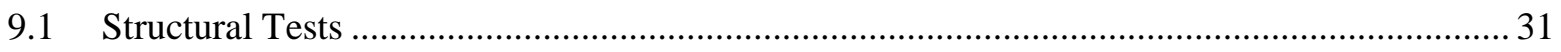

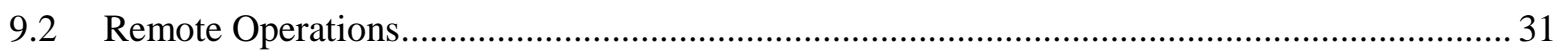

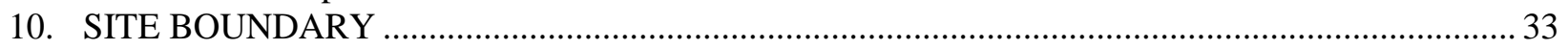

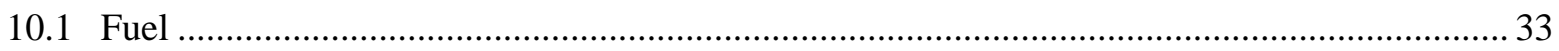

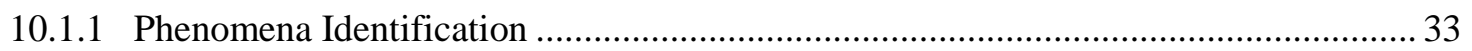

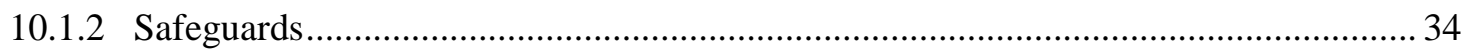

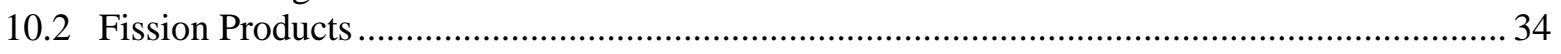

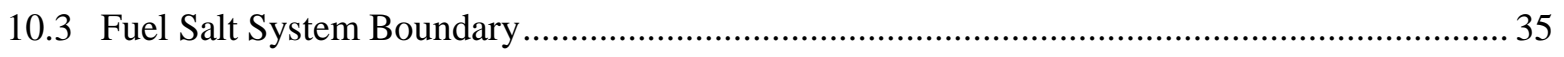

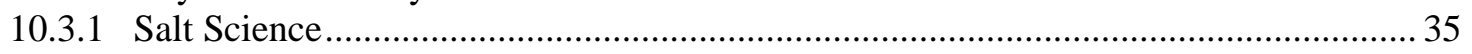

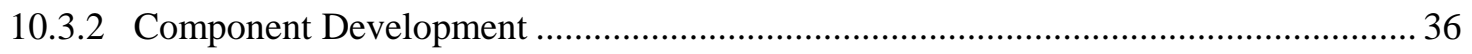

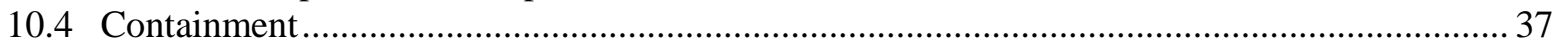

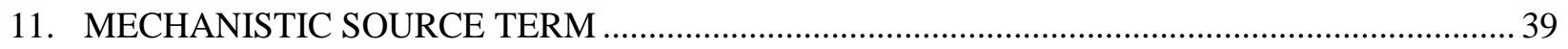

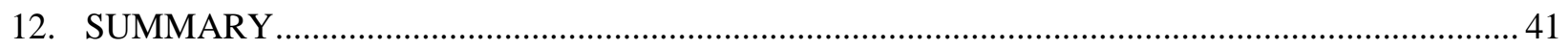

12.1 Trajectory Issues under Consideration by the NRC ........................................................ 41 
12.1.1 SECY-18-0060, Achieving Modern Risk-Informed Regulation .................................. 41

12.1.2 Draft Guidance to Implement the LMP ..................................................................... 42

12.1.3 NEI Proposed Physical Security Requirements for Advanced Reactors ..................... 42

12.1.4 Proposed Rulemaking on Emergency Planning......................................................... 42

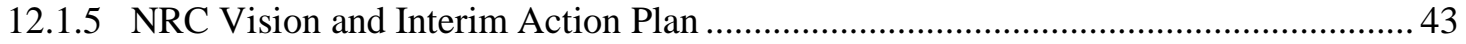

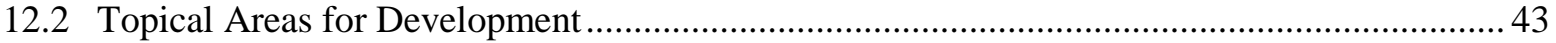

12.3 Summary of Specific Tasks Identified in the Roadmap Text ................................................ 44

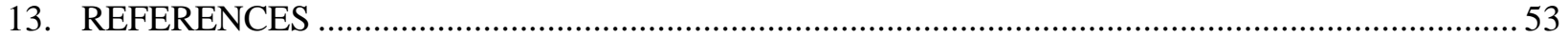




\section{FIGURES}

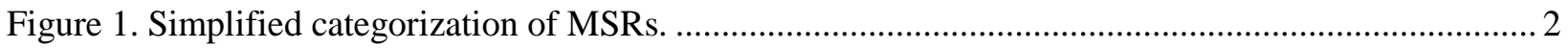

Figure 2. Review factors for advanced reactor licensing and safety issues ............................................ 3

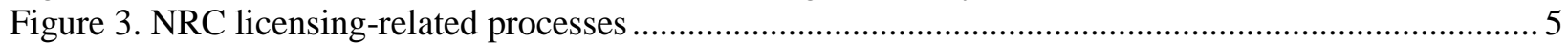





\section{ACRONYMS}

\begin{tabular}{|c|c|}
\hline ANL & Argonne National Laboratory \\
\hline ANS & American Nuclear Society \\
\hline $\mathrm{AOO}$ & anticipated operational occurrence \\
\hline ART & Advanced Reactor Technologies \\
\hline ASME & American Society of Mechanical Engineers \\
\hline BDBA & beyond design basis accident \\
\hline BPVC & Boiler and Pressure Vessel Code \\
\hline CFCC & continuous fiber ceramic composites \\
\hline DBA & design basis accident \\
\hline COL & combined license \\
\hline DCD & design control document \\
\hline DG & draft guide \\
\hline DOE & US Department of Energy \\
\hline DOE-NE & US Department of Energy, Office of Nuclear Energy \\
\hline EPZ & emergency planning zone \\
\hline FHR & fluoride salt-cooled high-temperature reactor \\
\hline FSAR & final safety analysis report \\
\hline HTGR & high-temperature gas-cooled reactor \\
\hline I\&C & instrumentation and control \\
\hline IAEA & International Atomic Energy Agency \\
\hline IAP & implementation action plan \\
\hline INL & Idaho National Laboratory \\
\hline $\mathrm{LBE}$ & licensing basis event \\
\hline LMP & Licensing Modernization Project \\
\hline LOCA & loss-of-coolant accident \\
\hline LSTL & liquid salt test loop \\
\hline LWR & light water reactor \\
\hline MSR & molten salt reactor \\
\hline MSRE & Molten Salt Reactor Experiment \\
\hline $\mathrm{NE}$ & Office of Nuclear Energy \\
\hline NEI & Nuclear Energy Institute \\
\hline NEUP & Nuclear Energy University Program \\
\hline Non-LWR & non-light water reactor \\
\hline NRC & US Nuclear Regulatory Commission \\
\hline ORNL & Oak Ridge National Laboratory \\
\hline PRA & probabilistic risk assessment \\
\hline PSAR & preliminary safety analysis report \\
\hline QA & quality assurance \\
\hline $\mathrm{R} \& \mathrm{D}$ & research and development \\
\hline RG & Regulatory Guide \\
\hline SBI & Small Business Initiative \\
\hline SECY & Commission paper \\
\hline SNL & Sandia National Laboratories \\
\hline SSC & structures, systems, and components \\
\hline TRISO & tristructural isotropic \\
\hline V\&V & verification and validation \\
\hline
\end{tabular}





\section{OVERVIEW}

Molten salt reactors (MSRs) both inherently and through good design possess highly desirable safety attributes. Successful commercial deployment of MSRs is heavily dependent on establishing their safety characteristics in a well-coordinated licensing requirements program. The approach outlined is based on adapting the MSR licensing process to the current light water reactor (LWR)-based Nuclear Regulatory Commission (NRC) process that exists today, which has been the traditional approach used by new technologies such as the Pebble Bed Reactor licensing application, the Clinch River Breeder Reactor licensing application, and more recently the NuScale licensing application. NRC has recognized some of the unique passively safe aspects of advanced non-LWR reactors and has introduced an advanced reactor strategic plan which will address policy issues that need to be addressed to accommodate advanced reactor concepts within the existing regulatory framework. Examples of some of these policy issues are the use of functional containment, the use of mechanistic source terms, and more reliance on performance-based and risk-informed regulatory processes, such as the Licensing Modernization Project, which emphasizes the use of risk-informed processes to select licensing basis events (LBEs), safety categorization of structures, systems, and components (SSC), and well-defined defense-in-depth systems. Applying performance-based, risk-informed regulatory processes is, consequently, vital to substantially decreasing the cost, time, and uncertainty of commercial MSR reactor licensing while providing for the health and safety of the public and protecting the environment. This document is intended to provide a roadmap for the licensing and safety activities necessary to provide a success path to commercialization.

Successful commercial deployment of MSRs should include the Department of Energy (DOE) working closely with industry and the NRC to identify and resolve key licensing and regulatory issues for advanced reactor developers, future owner/operators, and other affected industry stakeholders. The application of unique DOE national laboratory resources, intense and focused stakeholder engagement, and impactful collaborations that establish key parts of the necessary regulatory pathway for all nonLWRs, including MSRs, will support the establishment of the necessary regulatory infrastructure to bring these advanced reactors to commercialization in an economic and timely manner. The goal of all activities summarized in this plan is the establishment of a licensing path for MSRs that is sufficiently well defined so that MSR developers, their sponsors, and interested owner/operators can move forward with increased regulatory clarity and reasonable assurance of timely, cost-efficient deployment.

The four primary constituents of the regulatory framework that must be established to significantly reduce regulatory uncertainty for MSRs address three basic issues, which are summarized below:

A. Adequacy of the regulations

1. Establish or update NRC policies as applicable to MSR topics.

2. Develop adaptations and updates to NRC's existing LWR-based regulations and regulatory guidance.

B. Technology-specific technical requirements for satisfying the regulations

3. Define requirements based on testing and R\&D (fuel performance, salt science, decay heat removal, etc.), including associated industry codes and standards.

C. Process for predictable and timely NRC review of a submitted license application

4. Establish methods that encourage incremental and frequent NRC feedback on specific technology development issues and early design efforts (i.e., enable a "staged licensing review").

This report references the NRC's current structure for LWR application reviews and notes the research areas for DOE to support MSR licensing. DOE national laboratories provide resources such as staff experienced in advanced reactor technologies, experimental facilities, and technical information useful to NRC and industry in addressing these issues. Regulatory development activities then utilize these 
resources to propose and support adaptations and changes to the existing LWR-based regulatory framework so that it can be applied to MSRs. Active and ongoing collaborations among the stakeholders, including DOE/NRC interface, are vital to ensuring that priority R\&D is closely aligned with regulatory framework development so that MSR licensing and safety do not impact the critical path to MSR deployment.

The number of possible salts and material combinations leads to a broad range of potential MSR concepts. However, for a basic representation, MSRs can be classified into the following groups:

1. Salt-cooled reactors, in which a solid fuel undergoes fission and is cooled by a separate, nonfueled primary system salt, and

2. Salt-fueled reactors, in which a flowing fuel salt contains fissile material that fissions when in the core and flows throughout the primary system serving as fuel and coolant.

Salt-fueled and salt-cooled MSR concepts have many common technology needs. Examples include affordable fabrication and construction methods, large-scale salt production, large-scale pumping and heat exchange, source-term definition and behavior characterization, and modeling and simulation tools to evaluate performance and safety to facilitate licensing.

Both salt-cooled and salt-fueled concepts can be fast, epithermal, or thermal spectrum reactors. However, salt-cooled concepts of current interest are mainly thermal spectrum concepts that use fluoride salts as the primary coolant. This class of reactor, known as fluoride salt-cooled high-temperature reactors (FHRs), has been the subject of much of the recent MSR research. Salt-fueled thermal spectrum reactors typically use fluoride salts with fixed moderating material within the core. Fast spectrum salt-fueled concepts can use fluoride or chloride salts and do not require in-core moderating material. Less recent research has been performed on salt-fueled MSRs. For the purposes of this document, MSRs are broadly categorized as salt-fueled chloride-fast, salt-fueled fluoride, and salt-cooled fluoride reactors, as shown in Figure 1.

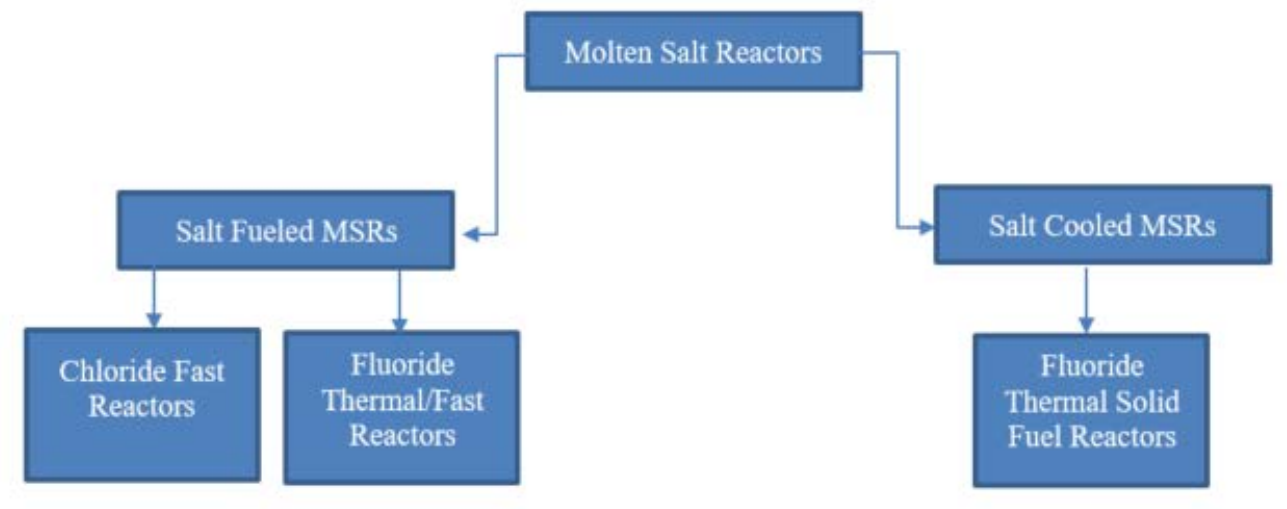

Figure 1. Simplified categorization of MSRs.

While there are significant subdivisions within these categories, for this roadmap, the two high-level categories are sufficient to describe and capture the general needs of MSRs. These categories will be specifically referred to as salt-fueled MSRs and FHRs. In cases where both categories are considered simultaneously, the reactors will collectively be referred to as MSRs. 


\section{DESCRIPTION OF WORK}

Some activities to establish a well-defined licensing path for MSRs that offers increased regulatory clarity and reasonable assurance of timely, cost-efficient deployment have previously been completed or are under way within the Regulatory Support area of the Advanced Reactor Technologies (ART) Program. A multi-lab team [Argonne National Laboratory (ANL), Idaho National Laboratory (INL), and Oak Ridge National Laboratory (ORNL)] familiar with the technical details of the technologies and experienced in regulatory requirements development and licensing are engaged with industry [e.g., Nuclear Energy Institute (NEI), etc.] and NRC stakeholders to develop and integrate elements of the regulatory framework in conjunction with the ART Program technology campaigns. Licensing and safety factors to facilitate the review of an advanced reactor design have evolved from the modular high-temperature gas reactor design. These factors have been shared with NRC and are shown graphically in Figure 2. This figure has been used in numerous licensing and safety discussions.

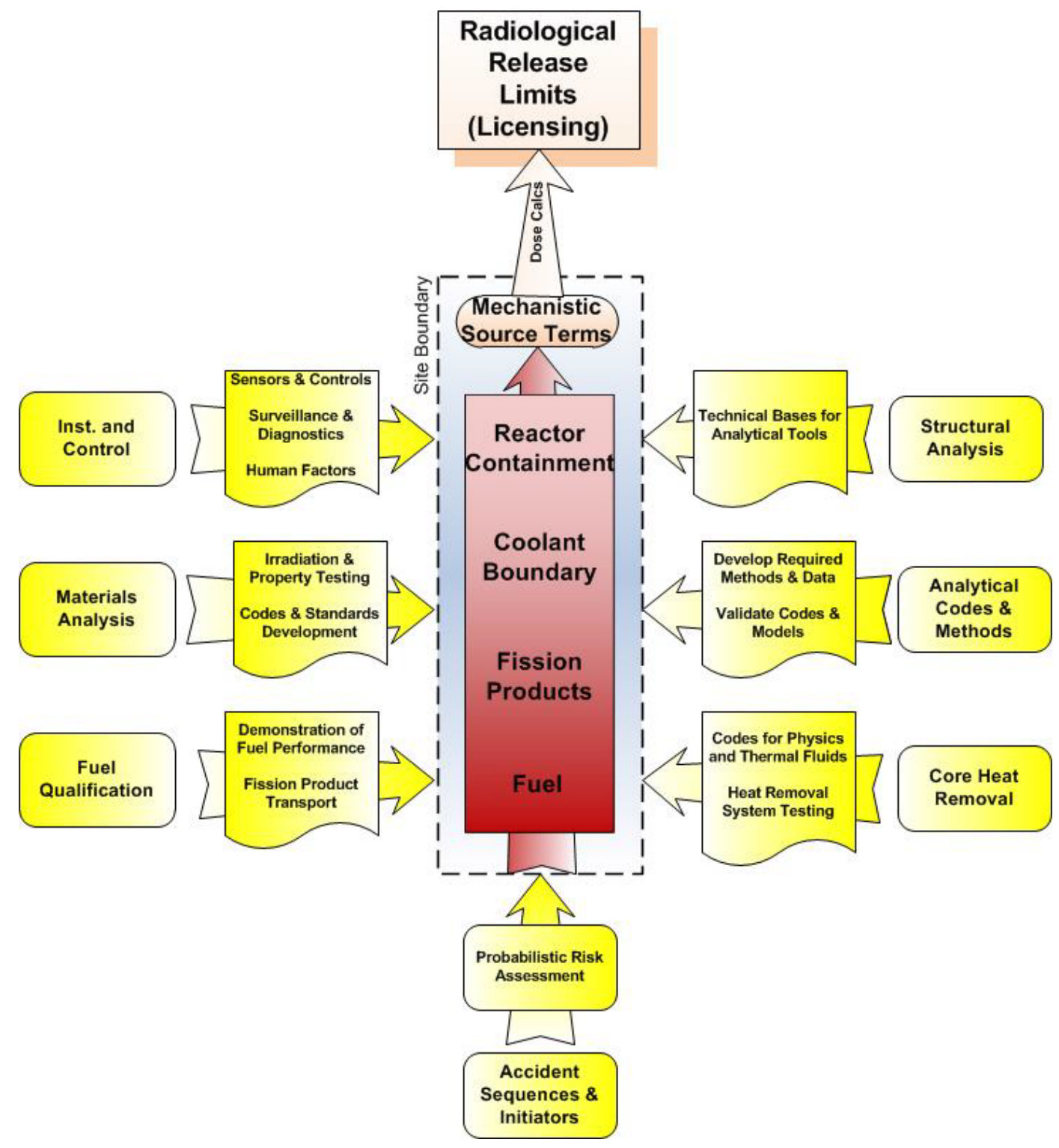

Figure 2. Review factors for advanced reactor licensing and safety issues. 
Figure 2 represents the factors to be addressed when establishing the regulatory basis for licensing various reactor technologies, including the existing LWR operating fleet. The issues and challenges regarding Commission policy, existing NRC regulations, and existing regulatory guidance are generally related to the "roots" and "trunk" of this licensing tree. The challenges with establishing and licensing technical requirements, typically through focused $R \& D$ and testing programs, are related to the "branches" of this tree. All portions of the tree must ultimately be addressed and resolved in an integrated way to allow reactor developers, prospective owner/operators, and NRC to establish reasonable assurance that operation of the proposed facility does not pose an undue risk to public health and safety nor to the environment.

Therefore, it was decided to base an initial MSR licensing and safety program for commercialization on the factors depicted in this diagram. The following sections of the report outline licensing and safety activities that are required, including an assessment of the level of readiness or difficulty for each factor and what remains to be done. In some cases, the section will simply summarize efforts that are under way and the expected results or time frame.

The roadmap is not design specific. It does assume the development of engineering demonstrations or commercial prototype reactors, but it does not recommend which MSR concepts to develop. Selections of specific salts, structural materials, and other technology choices place each MSR concept at a different stage along the development path with different development needs. These selections result in different technology needs, gaps, and schedules.

\subsection{INTERACTING WITH THE NRC}

NRC has developed a process for licensing nuclear power reactors based upon paragraph 103 of the Atomic Energy Act of 1954 and its amendments and the Energy Reorganization Act of 1974. The legal requirements are principally embedded in two sets of reactor-focused regulations: (1) 10 CFR 50, "Domestic Licensing of Production and Utilization Facilities," which has been the basis for all the power reactors in operation today (with the exception of facilities owned by DOE or the Department of Defense), and (2) 10 CFR 52, "Licenses, Certifications, and Approvals for Nuclear Power Plants," which has been used for the Generation III and III+ reactor licensing process since 1997. Additionally, 10 CFR 20, "Standards for Protection Against Radiation,” applies to all reactors. The NRC staff determines whether a reactor design ensures adequate protection of public health and safety and is in accordance with the common defense and security.

A regulatory review roadmap ${ }^{1}$ is available for advanced reactor designers to understand the options available for interacting with the NRC staff. Less formal interactions are available through the preapplication process, and more formal interactions are available through a variety of applications. NRC is working to improve its readiness to regulate non-LWR technologies, as outlined in Section 2.2. The roadmap outlines appropriate interactions between the NRC staff and stakeholders at various stages of the reactor design process.

The NRC staff notes in the roadmap document that regulatory requirements have evolved and increasingly reflect NRC's adoption of a risk-informed, performance-based regulatory framework. Hence, current efforts to define appropriate regulatory approaches for non-LWRs provide an opportunity to develop a technology-inclusive framework to ensure the fundamental safety functions are fulfilled in a manner commensurate with the risks associated with specific technologies or designs. However, it should be noted that non-LWR technologies should incorporate features and characteristics consistent with expectations set forth in the NRC Advanced Reactor Policy Statement. ${ }^{2}$ The policy states:

Regarding advanced reactors, the Commission expects, as a minimum, at least the same degree of protection of the environment and public health and safety and the common 
defense and security that is required for current generation LWRs. Furthermore, the Commission expects that advanced reactors will provide enhanced margins of safety and/or use simplified, inherent, passive, or other innovative means to accomplish their safety and security functions.

Figure 3, taken from the NRC roadmap document, illustrates the various NRC staff interaction and regulatory paths available to an applicant or vendor. The figure shows the opportunity for pre-application discussions with the staff early in the design process, including meetings, topical reports, white papers, conceptual design reviews, etc. Following down the left side of the figure, the traditional two-step licensing process under 10 CFR 50 is an option as the design matures. This may be the preferred path for the first-of-a-kind technology with a relatively high-technology readiness. The center of the figure identifies opportunities for interaction with the staff outlined under 10 CFR 52. These include formal review of substantial portions of a plant design under the standard design approval process, complete design reviews under the design certification process, and one-step licensing under the combined license process.

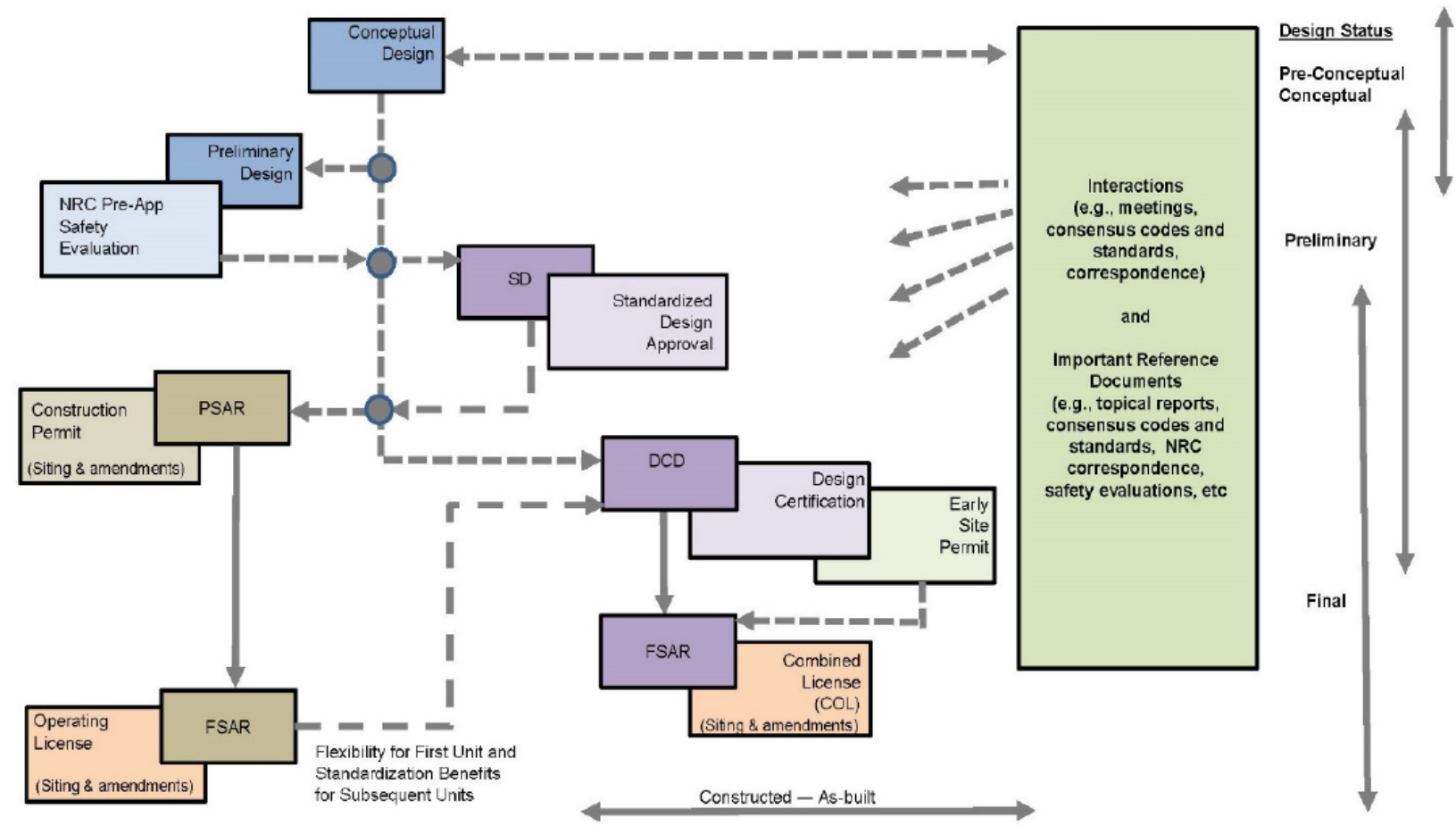

Figure 3. NRC licensing-related processes (source: Regulatory Review Roadmap, ML17312B567).

The NRC roadmap notes that the primary interactions between NRC staff and reactor designers, industry organizations, and other stakeholders include the following:

- Meetings: Meetings with NRC staff can provide initial feedback on design options and support ongoing reviews of submitted material. NRC staff can hold meetings with individual designers, technology or design-centered groups, industry organizations, DOE Office of Nuclear Energy (DOE-NE), and other stakeholders. The feedback a designer receives from NRC during meetings can include preliminary questions from NRC staff on the design, sharing regulatory perspectives with the designer, or NRC staff describing needed information to complete a more formal review supporting a higher-level outcome. 
- White papers, and technical reports: Letters and reports outlining policy or technical positions can be used to provide information to NRC staff and to solicit feedback in the form of initial, conditional, or conclusive regulatory positions. Although NRC has no formal guidelines or naming conventions for these interactions, the following describes the agency's general practices.

o Documents often referred to as white papers can be used to request general feedback or to obtain preliminary regulatory responses (e.g., a template could be submitted to propose a reasonable format and content for a submittal) or a more formal regulatory decision (e.g., applicability of a regulatory requirement to the design). Staff responses for these types of documents are generally less specific and provide less regulatory certainty than responses for topical reports and formal applications.

o Documents often referred to as technical reports can be used to provide results of research, testing, or analyses that help verify or validate computer models, expected performance of components or systems, or other supporting information of an application. NRC's assessment of the relevance and adequacy of technical reports is usually documented in safety evaluations related to specific topical reports or applications.

- Topical reports: A topical report is a stand-alone report containing technical information about a reactor, SSC, or safety topic that can be submitted to NRC for its review and approval. Topical reports improve the efficiency of the licensing process by allowing the staff to review proposed methodologies, designs, operational requirements, or other subjects for subsequent referencing in licensing applications. An NRC-approved topical report can provide a technical basis for a licensing action.

- Consensus codes and standards: NRC encourages the development and use of consensus codes and standards as part of its regulatory programs and can incorporate the codes and standards into regulations and guidance documents.

- Rulemaking and regulatory guidance development: Stakeholder input can be provided and is encouraged when NRC is considering new or revised regulations or regulatory guidance documents (e.g., interim staff guidance, standard review plans, design-specific review standards, and regulatory guides).

- Research and development plans: Entities may submit R\&D plans supporting reactor technologies or designs. This information is useful for NRC to be aware of what data may become available for verification and validation (V\&V) of computer models, what test facilities may need to be inspected for quality assurance (QA), and which tests NRC may wish to observe.

These interactions can be used to exchange information between designers and NRC staff. The interactions can result in NRC providing varying degrees of feedback for use in the design process and application development for licenses, certifications, or design approvals. Interactions between staff and individual vendors or applicants typically incur a cost for NRC staff time. Broad interactions between technology stakeholders and NRC staff leading to technology-inclusive policies and regulatory actions generally do not incur a cost.

\subsection{NRC ADVANCED REACTOR IMPLEMENTATION ACTION PLANS}

As noted in Section 2.1, NRC is improving its readiness to regulate non-LWR technologies. In 2017, NRC proposed near-term implementation action plans (IAPs) ${ }^{3}$ regarding the new generation of advanced non-LWRs. The plans include technical readiness, regulatory readiness, and staff communication regarding expected future licensing applications for non-LWR designs. There are six individual strategies addressed in the near-term IAPs. 
1. Acquire/develop sufficient staff knowledge, technical skills, and capacity to perform non-LWR regulatory activities.

2. Acquire/develop sufficient computer codes and tools to perform non-LWR regulatory reviews.

3. Establish a flexible non-LWR regulatory review process within the bounds of existing regulations, including the use of conceptual design reviews and staged-review processes. This flexibility will accommodate potential applicants having a range of financial, technical, and regulatory maturity and a range of application readiness.

4. Facilitate industry codes and standards needed to support the non-LWR life cycle (including fuels and materials).

5. Identify and resolve technology-inclusive (not specific to a particular non-LWR design or category) policy issues that impact regulatory reviews, siting, permitting, and/or licensing of nonLWR nuclear power plants.

6. Develop and implement a structured, integrated strategy to communicate with internal and external stakeholders having interests in non-LWR technologies.

NRC has also laid out mid- and long-term IAPs ${ }^{4}$ that support NRC's readiness to license and regulate advanced non-LWR reactor designs in an effective, efficient, and predictable manner. Collectively, these IAPs should provide guidance as DOE interfaces with NRC in supporting MSR developers, future owner/operators, and other affected industry stakeholders for licensing interactions with NRC.

\subsection{ORNL STATEMENT ON NRC WORK AND DOE WORK}

ORNL has a support task with NRC to assist them in developing an advanced reactor regulatory infrastructure. Consideration of fuel qualification criteria for salt-fueled MSRs is part of this support. The purpose of the work is to help NRC understand the unique challenges associated with the MSR fuel form (e.g., the fuel chemistry is continuously changing during reactor operation, and the fuel is transported within and outside the core). These (and other) challenges require new NRC policies to ensure that the fuel qualification process is flexible enough to apply to the expected spectrum of MSR fuel designs under development. The MSR policies must also provide high confidence that the physical and chemical behavior of fuel is sufficiently understood so that it can be adequately modeled for both normal and accident conditions, reflecting the role of the fuel design in the overall safety of the facility and the health and safety of the public. It is NRC's responsibility to develop the policy requirements and the applicant's responsibility to ensure that their designs meet them.

On the other hand, this DOE MSR licensing roadmap effort is intended to look at all the requirements to license an MSR in the United States. Fuel qualification is one aspect of such a licensing effort, but there are many more considerations that should be addressed. DOE support for the identification of MSR accident sequences and initiators will ultimately provide an applicant insight into defense-in-depth issues, minimum safety equipment, and security, including vital area identification. Appropriate instrumentation and controls, including environmental effects testing, is needed to address appropriate surveillance and diagnostics, prepare MSR Technical Specifications, and provide appropriate human factors, such as manmachine interfaces. This is especially crucial in the high-radiation environment inside MSR containment. MSRs are expected to rely on a functional containment boundary made up of several independent layers, or barriers. These barriers will have to address radiation, strength, and corrosion issues. This will require a material analysis program and a structural analysis program. Modeling and simulation tools will need to be adapted to address homogeneous fuel. Finally, core heat removal, physics codes, and the chemistry of fuel qualification will need to be addressed for an applicant to successfully license an MSR. In subsequent sections, the MSR licensing roadmap will tie these licensing needs to the associated R\&D efforts necessary to support the eventual successful licensing of a commercial MSR. 
Fuel qualification is only one of many activities and is differentiated by a policy effort at NRC and R\&D efforts at DOE. Fuel chemistry and physical property R\&D is necessary to ensure fuel qualification (thermal conductivity, density, melting point, boiling point, viscosity, fission product retention, materials compatibility, etc.) under variable salt and fuel formulations and a spectrum of operating conditions. Fuel qualification is discussed in detail in Section 4. 


\section{PROBABILISTIC RISK ASSESSMENT}

Probabilistic risk assessment (PRA) techniques play a more important role in the safety analysis of the design of advanced reactors compared to that of existing plants. Application of PRA techniques during the design process can influence the safety and economics of the design on the front end by influencing the selection of safety-related SSC and defense-in-depth strategies based on the selection of appropriate LBEs. An industry-led team of licensing and advanced reactor technology subject matter experts, prospective advanced reactor technology license applicants, and several current fleet owner-operators is working to provide an updated regulatory framework to facilitate risk-informed and performancebased selection of LBEs for advanced non-LWRs.

The updated regulatory framework, referred to as the Licensing Modernization Project (LMP), was initiated in April 2016 to bring important insights and deployment considerations to the overall advanced reactor licensing strategy. The LMP is supported through a cost-sharing arrangement with the DOE Office of Nuclear Energy (NE) and private industry. LMP efforts are closely coordinated with the NEI and are directly associated with NRC IAP Strategy 5 to identify and resolve technology-inclusive policy issues that impact the regulatory reviews, siting, permitting, and/or licensing of non-LWR nuclear power plants, including MSRs. The DOE interface is managed through INL.

\subsection{LICENSING BASIS EVENT SELECTION}

The root of the licensing tree, depicted in Figure 2, is the selection of accident sequences and initiators (or LBEs) for a particular design. Using design-specific PRAs, anticipated operational occurrences (AOOs), design basis accidents (DBAs), and beyond design basis accidents (BDBAs) are defined from the event sequence families determined in the LBE process. The minimum starting set of AOOs and DBAs are evaluated in NUREG-0800, ${ }^{5}$ Chapter 15, “Transient and Accident Analysis.” This forms the basis for establishing safety-related SSC to prevent or mitigate AOOs and DBAs and those defense-in-depth systems to adequately supplement AOO, DBA, and BDBA mitigation. Therefore, the appropriate selection of LBEs that represent all the events that challenge the safety aspects of the design is critical to MSR safety and licensing reviews.

The LMP team, led by Southern Company, has issued a report ${ }^{6}$ that proposes the development of a framework for the efficient licensing of advanced non-LWRs. This effort aims to provide a technologyinclusive, risk-informed, and performance-based approach to identify a full set of LBEs for the design and licensing of advanced non-LWRs based on an evolving PRA model for the technology or design. A key licensing outcome of this proposed process is a structured, systematic, and reproducible process for the selection of bounding DBAs for advanced non-LWR plants.

The proposed LMP approach, using the design-specific PRA, is designed to ensure that an appropriate set of limiting events for each reactor technology is reflected in the selection of DBAs and that the full set of LBEs defines the risk significant events for each design and technology. Evaluation of LWR-based DBAs is avoided in this process. Unfortunately, there are no publicly available MSR designs with an established PRA. An early MSR licensing task must focus on LBE selection because this determines SSC classification, SSC performance, accident modeling, etc.

Task 3.1.1 - LBE Selection for Salt-fueled MSRs: No specific MSR design is advocated by this roadmap. However, it is important that an appropriate set of basic salt-fueled MSR LBEs be developed. An expert panel should be convened to define MSR generic sets of accidents beginning with a master logic diagram to focus efforts. The expert panel should consider the LMP process, the brief operating history of salt-fueled MSRs, and expert judgment. This effort should support development of ANS 20.2, "Nuclear Safety Design Criteria and Functional Performance Requirements for Liquid-Fuel Molten-Salt Reactor Nuclear Power Plants.” This task will subsequently support the development of accident- 
initiating events and the development of accident sequences. This task will then directly support the development of salt-fueled MSR accident analysis codes. This approach is necessary because there is no publicly available salt-fueled MSR design with an established PRA.

Task 3.1.2 - LBE Selection for FHRs: No specific FHR design is advocated by this roadmap. However, it is important that an appropriate set of FHR LBEs be developed. An expert panel should be convened to define FHR generic sets of accidents beginning with a master logic diagram to focus efforts. Because the FHR has characteristics of both liquid-metal reactors and high-temperature gas reactors, this effort can draw on experience already gained in evaluating those technologies. A recent study examined initiating events for these two reactor classes. ${ }^{7}$ This study should be expanded to include FHRs. This effort should support development of ANS 20.1, "Nuclear Safety Criteria and Design Process for Fluoride Salt-Cooled High-Temperature Reactor Nuclear Power Plants.” This task will subsequently support the development of FHR accident sequences and will then directly support the development of FHR accident analysis codes.

\subsection{USE OF PROBABILISTIC RISK ASSESSMENT}

As proposed MSR designs begin to mature, initial PRAs should be established. The PRA can iteratively affect the early stage of design with the understanding that the scope and level of detail of the PRA will be consistent with the level of detail of the evolving design and site characteristics. Subsequent plant PRA reviews are then performed at various discrete points along the entire reactor design-operation life cycle to support the reactor design and provide iterative risk insights for the selection of LBEs, safety classification of SSC, and risk-informed evaluation of defense-in-depth.

Although deterministic, qualitative results from the PRA will provide representative and mitigating design strategies and alternatives, appropriate event frequencies must be established for advanced reactor technologies. In addition, the treatment of uncertainties must be considered as both the design and the PRA evolve. As noted previously, information developed in the PRA is subsequently used to help evaluate the SSC responsible for preventing and mitigating AOOs and DBAs. Subsequently, the PRA can be used to support the identification of emergency planning specifications and the development of Technical Specifications.

Task 3.2.1 - Determine Event Frequency and Uncertainty: Estimates of the salt-fueled MSR and FHR event frequencies will need to be generated for the initiating events. Appropriate treatment of uncertainties will need to be emphasized. This will directly support the iterative evaluation of the safety classification of generic SSC (Tasks 3.3.1 and 3.3.2). This task follows Tasks 3.1.1 and 3.1.2. The task will drive R\&D requirements for SSC, support accident analysis, and support defense-in-depth considerations.

\subsection{CLASSIFICATION OF STRUCTURES, SYSTEMS, AND COMPONENTS}

LBE identification and analysis, as well as an evaluation of event frequencies, will identify the necessary safety functions to prevent or mitigate AOOs and DBAs. As part of the LBE selection and evaluation process described in Section 3.1, the advanced non-LWR designer will select an initial set of safetyrelated SSC that are necessary and sufficient to perform the safety functions required to mitigate all the DBAs within the 10 CFR 50.34 dose limits using conservative assumptions. As the PRA matures, the selection of the minimum set of safety-related SSC will evolve.

Task 3.3.1 - SSC Classification: Categorize safety-related salt-fueled MSR and FHR SSC. The safety classification determines the level of scrutiny applied to these SSC over the lifetime of the reactor and defines their failure thresholds. The safety classification of SSC will be determined by a combination of deterministic and probabilistic methods. This task follows Task 3.2.1 and will drive R\&D requirements for SSC, support accident analysis, and support defense-in-depth considerations. 


\subsection{DEFENSE-IN-DEPTH}

The LMP report includes guidelines for establishing, evaluating, confirming, and documenting the adequacy of defense-in-depth for advanced non-LWR technologies. The defense-in-depth philosophy implies that multiple independent but complementary methods are in place to protect the public from potential harm because of nuclear reactor operation. Realization of an adequate defense-in-depth plan results from a series of risk-informed performance-based decisions in which defense-in-depth attributes are incorporated into the design, operations, and maintenance of the plant. Rather than relying on engineering judgment and past LWR practices, PRA, selection of LBEs, safety classification of SSC, and specification of performance requirements for SSC are key factors that shape the appropriate level of defense-in-depth for an advanced non-LWR.

Task 3.4.1 - Determine Defense-In-Depth Systems: Categorize defense-in-depth salt-fueled MSR and FHR SSC. Based on the results on Task 3.3.1, identify defense-in-depth SSC that may require special regulatory treatment because of their function to supplement the safety-related SSC in mitigating AOOs, DBAs, and BDBAs. For example, current LWRs use barriers for defense-in-depth to protect the public health and safety - fuel, cladding, reactor vessel, and containment. A risk-informed defense-in-depth approach for MSRs may use different metrics to select defense-in-depth SSC.

\subsection{REGULATORY GUIDANCE}

NRC advanced reactor meetings are held approximately every 6 weeks that include a wide variety of policy topics. These activities support NRC IAP Licensing Strategy 3 to establish a flexible non-LWR regulatory review process within the bounds of existing regulations, including the use of conceptual design reviews and staged-review processes. The expectation is that NRC staff will use current LWR documents to subsequently prepare much of the regulatory guidance needed to license advanced nonLWR designs. This is a multiyear process.

Task 3.5.1 - MSR Guidance Document Support: In addition to the near-term LMP effort, DOE should provide longer-term specific support of MSR licensing review documents. Essentially, this is the root structure for the licensing tree depicted in Figure 2. The policy, regulations, and guidance for unique technologies need to evolve such that an eventual MSR application will move efficiently through the licensing process. Licensing evaluations for commercial MSRs are anticipated to be like those for other advanced reactor concepts, the details of which are not fully developed. An evaluation of Regulatory Guide (RG) $1.206^{8}$ and NUREG-0800, Chapter 4, "Reactor"; Chapter 5, "Reactor Coolant System and Connected Systems”; Chapter 6, "Engineered Safety Features”; and Chapter 9, “Auxiliary Systems” (includes gas system, filters, and fission product traps), should be considered for MSR technologies. These NUREG-0800 chapters will likely be the most impacted by MSR technology and should be evaluated to determine changes needed for better applicability to MSRs. Generic MSR licensing issues deemed important to a wide population of potential applicants will generally receive NRC staff feedback at no cost to DOE. Support for licensing issues related to a specific MSR design concept can subsequently be considered separately and in a manner that properly protects intellectual property.

Task 3.5.2 - Review of Supporting and Guidance Documents: As a trickle-down task from Task 3.5.1, all supporting documentation identified by Task 3.5.1 should be reviewed for applicability to MSR technology. DOE should suggest approaches to make these supporting documents (RGs, NUREGs, etc.) more performance based with respect to MSR technology. This will facilitate future technology-specific interactions between individual vendors/applicants and NRC staff. Otherwise, technology advances, experimental results, and data acquisition may be hampered by an ill-equipped review process.

Further effort will be needed to generate a preliminary licensing strategy for a demonstration or test reactor, which will likely require NRC staff development and the use of an MSR version of NUREG-1537. ${ }^{9}$ A separate NUREG-1537 effort led by Southern Company and TerraPower under a cost- 
share agreement with DOE, and supported by NEI, is currently under way. A DOE-sponsored proposal for an update to NUREG-1537 for salt-fueled MSRs was recently released. ${ }^{10}$ FHRs should be able to be reviewed using the existing guidance. 


\section{FUEL QUALIFICATION}

No commercial reactors have sought to use liquid fuel. As a result, the regulatory system in the United States has evolved around heterogeneous and solid-fueled systems. Commercial reactor regulation in the United States is based upon demonstration of compliance with specific design criteria and fuel performance requirements derived from the reactor's general design criteria. Heterogeneous fuel in current reactors is considered the first and perhaps the most important barrier in the prevention of radiological material released to the public and environment during both normal and off-normal operation. Therefore, extensive effort has been placed on ensuring that the behavior of the fuel is well understood under all perceived reactor operational conditions, even after the fuel is removed from the core.

This process, imposed by regulations, is generally referred to as fuel qualification. For a new solid fuel, qualification begins with research on the physical behavior of the fuel and its associated cladding material during normal operation conditions. Qualification then involves irradiation of the fuel and cladding to fluxes like that expected to be received over the lifetime of the fuel. In addition, the fuel and cladding material are tested under transient conditions like those that might occur during accidents. In each case, the fuel is carefully examined for defects/failures and fuel performance simulation codes are developed based on this information. The existing fuel qualification process is well established and highly structured.

It can take as long as 25 years and require hundreds of millions of dollars to conceive, develop, and qualify a fuel design for use in a commercial reactor. The time and expense of fuel qualification is one of the most significant impediments to the introduction of advanced reactors or innovative fuel designs into the commercial market. This process would include FHR fuel. This section supports regulatory action for salt-fueled MSR fuel qualification and comments on the status of FHR fuel qualification.

Fuel qualification interfaces with code development, mechanistic source terms, and heat removal systems. The code development task involves identification of fission products, quantity, and location as a function of time. Aspects of the current NRC review of fuel are included in NUREG-0800, Chapter 4, "Reactor"; Chapter 5, "Reactor Coolant System and Connected Systems"; Chapter 6, "Engineered Safety Features”; and Chapter 15, "Transient and Accident Analysis.”

\subsection{DEMONSTRATION OF LIQUID FUEL PERFORMANCE}

Salt-fueled MSRs are unique. Because the fuel is liquid, there is no accumulation of mechanical effects such as stress, creep, and swelling. However, salt-fueled reactors must demonstrate compliance with the regulatory design criteria addressing fuel condition degradation, radionuclide retention, reactor stability and negative reactivity feedback, and heat removal. In salt-fueled MSRs, the chemical composition of the fuel changes constantly due to

1. fissioning of the fuel, with attendant introduction and removal of fission products,

2. chemical interactions of fuel with the fuel system boundary walls,

3. composition adjustments by the chemical control system, and

4. changes in actinide composition.

One aspect of salt-fueled MSRs is that the fuel is also the coolant. Thus, the fuel is not only the principal heat source, it also plays a major role in heat removal both for normal operations, off-normal events, as well as during shutdown (decay heat removal). Because fission products are produced in the fuel as a result of the fission process, the presence of these materials will change the chemical composition of the 
fuel salt and in turn change the thermal physical properties of the fuel/coolant. Changes in fuel salt composition may affect the ability to remove heat from the reactor. For instance, changes in fuel salt composition may change the melting point or boiling point of the fluid, the viscosity, and thermal properties such as heat capacity or convective heat transfer characteristics. Fuel salt composition changes may also result in the plate-out of materials on the piping or vessel walls, especially in low-temperature regions. Addition of materials such as fission products created during the fission process or conversion of fertile to fissile isotopes may also affect the solubility of materials or the corrosiveness of the salt. All of this occurs over varying time intervals. Understanding the impact of changing thermal physical properties of the fuel/coolant because of the addition of fission products and possible corrosion product impurities will be essential to analyses of the ability to remove heat from the fuel both during normal and off-normal conditions and after shutdown.

Another aspect of salt-fueled MSRs is that the fuel is molten. Because the fuel is a liquid, understanding the mechanical behavior of the fuel/cladding/subassembly and core structures will not be an important fuel qualification factor since there are no permanent mechanical stressors in liquids. MSR liquid fuels behave as single-phase Newtonian fluids. MSR fuel salts have a low vapor pressure and will not require operation at high pressures to prevent two-phase conditions from occurring. The fuel normally operates at several hundred degrees Celsius below its boiling point. The fuel salt is mobile and circulates not only in the reactor but also, in some reactor designs, outside the reactor vessel as well.

All fuel salts being considered are highly corrosive-some more than others. In addition, some fuel salts under consideration may contain hazardous materials such as beryllium. This may impact handling and maintenance operations, even for unirradiated fuel salt (requiring protective clothing, respirators, or use of glove boxes, training, policies, and procedures, etc.).

Salt-fueled MSRs have no cladding to contain the fission products; thus, the liquid fuel should be chemically compatible with the code-qualified materials that form the first containment boundary, such as the heat exchangers, pumps, valves, reactor vessel, storage tanks and piping, and any other materials it may contact, such as shielding and control assemblies. Because the fuel chemical composition will change slowly over time and will vary with temperature, the chemical compatibility with contacted materials may change over the lifetime of the reactor.

MSRs may have a significant part of the fuel contained outside the normal core (location where prompt fission occurs), such as in tanks, radwaste systems, cleanup systems, and piping. Fuel found in these systems will need to be cooled since it generates decay heat. The degree of heat removal needed outside the core may depend on the chemical composition and age of the fuel in these systems. Chemical compatibility with the surfaces of these containers needs to be ensured in a manner similar to that of the vessel and other components mentioned earlier.

Salt-fueled molten salt has a high melting temperature; therefore, its behavior as it cools below liquidus (freezing) needs to be well understood. Examples of such behavior are stratification, plate-out, dimensional changes during freezing, and decomposition.

NRC staff notes in its near-term IAPs that there is little information on MSR fuel performance, which makes it difficult to identify precise experimental needs and requirements. There is interest in some MSR concepts to use thorium (to breed fissile uranium-233), while other MSR designs plan to burn plutonium or depleted uranium. This tends to make fuel qualification more complex as it could be specific to each MSR concept.

NRC staff will need to determine the bounding envelope for the fuel characteristics that may affect the safety basis of the reactor as licensed. This determination of the time-varying properties that impact the safety basis provides the fuel performance licensing basis over the life of the core. Fuel salt properties that drift outside the established performance envelope (Technical Specifications) would need to be brought back within the performance envelope (chemical control) or result in the fuel exceeding its design criteria. 
A chemical approach to fuel qualification as opposed to a mechanistic approach would profoundly affect current thinking on fuel qualification. Therefore, the process and information that would be required by NRC needs to be defined early so that appropriate research and data collection can be initiated by the designers supported by DOE. It should be noted that based on the experience gained in the Molten Salt Reactor Experiment (MSRE), it appears that long-term irradiation effects on the fluoride-based fuel salts will play a much smaller role in MSR fuel salt qualification than they do in heterogeneous solid-fueled systems. In addition, geometric similitude is not likely a factor. Thus, much of the information needed may be obtainable from nonradioactive experiments such as separate effects and integral effects tests, which are shown to chemically behave in a manner similar to that of the fuel. Even surrogates could be used for materials such as plutonium if it can be shown that they have the same chemical behavior. It is assumed that chloride salt systems have similar resistance to irradiation damage, but experimental evidence is needed to verify this assumption.

Ongoing fuel performance chemistry work is being supported by DOE. In addition, ORNL has proposed work, to be funded by NRC, to support a paradigm shift in regulation regarding MSR fuel salt qualification as a chemical process.

Task 4.1.1 - Salt-fueled MSR Fuel Qualification: Research is necessary to support development of a salt-fueled MSR fuel qualification plan for the entire fuel cycle. Fuel qualification is a significant branch on the licensing tree depicted in Figure 2. Facets of the plan will include the following.

1. Fabrication
a. Flush salt
b. Fuel salt
c. Coolant salt

2. Packaging

3. Transportation

4. Storage

5. Unpacking

6. Fuel makeup
a. Chemistry
b. Technical Specifications

7. Normal operation and AOOs

8. Accidents

9. Source terms

10. Fission product transport

11. Used fuel processing

12. Used fuel storage

13. Used fuel transportation

\subsection{DEMONSTRATION OF FHR FUEL PERFORMANCE}

FHRs will use coated particle fuel. The next generation nuclear plant program has been developing tristructural isotropic (TRISO) coated particle fuel. ${ }^{11}$ Identical TRISO particles are directly applicable to FHRs. However, the physical characteristics of FHRs are different from those of high-temperature gascooled reactors (HTGRs) and will require different fuel qualification requirements. As a liquid-cooled 
reactor, acceptable FHR fuel performance also has similarities to that of LWRs. Prior TRISO fuel performance evaluations for HTGRs ${ }^{12}$ have relied upon analogies between TRISO and LWR fuel. LWRs have established, acceptable fuel performance specifications, providing a template to develop the requirements for FHRs. However, key steps to developing a mechanistic source term such as identifying design basis events and accident initiation sequences have yet to be performed for FHRs. Further FHR concept and technology development will be necessary before a comprehensive FHR fuel qualification plan can be developed.

The large margin provided by FHRs minimizes the precision necessary in modeling toolsets. Key LWR issues, such as critical heat flux to avoid boiling, or HTGR issues, such as localized flux peaking, are much less important to represent beyond what idealized models can provide. Further, several issues, such as flow-induced fuel vibration and flow distribution prediction within the core that are difficult to computationally model, can be physically modeled relatively inexpensively using simulant materials. Any detailed FHR fuel qualification computational modeling efforts thus need to focus on characteristics that need to be extrapolated outside of areas where inexpensive physical simulations or simplified computational models can provide adequate understanding.

\subsection{FISSION PRODUCT TRANSPORT}

Fission product transport is an important issue for salt-fueled MSRs. NRC uses MELCOR to estimate severe accident source terms in LWRs. Sandia National Laboratories (SNL) developed and maintains MELCOR for the NRC. NRC has commissioned SNL to adapt MELCOR for advanced non-LWRs, including MSRs. SNL staff has met with ORNL staff to obtain a better understanding of MSR technology. Therefore, development of MSR fission product transport models is not a DOE issue. NRC will fully support this effort. However, other code work will need DOE support, as outlined in other chapters in this roadmap. 


\section{CORE HEAT REMOVAL}

As noted in Section 2.1, NRC expects that advanced reactors will use simplified, inherent, passive, or other innovative means to accomplish their safety and security functions. Thermal-fluids phenomena are the physical processes involved in normal operation and DBAs. The focus is on the fluids involved in the reactor coolant system, as well as those in the intermediate heat exchange systems through the ultimate heat sink(s). The primary goal of thermal-fluid analysis is analysis of the safety systems necessary to remove decay heat following an incident. This requires an understanding of the core physics involved in the generation of decay heat. Passive MSR decay heat removal is a primary safety function requiring testing and validation. Further understanding is needed of (1) initialization and stabilization times during accidents, (2) the impact of changing fuel salt properties, and (3) the need to cool multiple locations (e.g., fission product traps). Validated modeling tools must be developed for this function. Experimental test data will be required for validation.

Core heat removal includes decay heat removal and normal heat transport. This task needs to include coupled reactor-physics models and heat transport models. Models for delayed neutron distribution are of interest. Licensing input interfaces include fission product transport, reactor-physics and heat transport models, and fuel qualification (thermal physical properties as a function of time) licensing inputs. Aspects of the current NRC review of core heat removal are included in NUREG-0800, Chapter 4, "Reactor"; Chapter 5, "Reactor Coolant System and Connected Systems”; Chapter 6, "Engineered Safety Features”; Chapter 9, “Auxiliary Systems”; and Chapter 15, “Transient and Accident Analysis.”

\subsection{CODES FOR PHYSICS AND THERMAL FLUIDS}

Several state-of-the-art physics codes and thermal-hydraulics codes have been developed and are in use in the LWR community. Some of these codes are summarized at the end of this section. It is essential that these codes or similar codes be adapted for the MSR community. Reactor kinetics and criticality, fuel performance, and thermal-fluid phenomena all need to be modeled to provide insight on salt-fueled MSR core heat removal. This is complicated by the time-varying properties of the MSR fuel salt, as discussed in Section 4.1, yet simplified by MSRs being a single-phase system.

DOE has sponsored efforts to enable criticality and fuel cycle simulations of MSRs in SCALE. Recent work includes developing computer codes for MSR reactor kinetics and criticality analysis in SCALE. Salt properties were also added to the PARCS code for analysis of an FHR.

DOE-sponsored thermal-fluid research is focused on delivering solutions to challenging fluid, heat transfer, and irradiation engineering problems in MSR systems by leveraging a unique integration of design, simulation, fabrication, and experimentation expertise. However, such efforts have been limited. Analysis efforts have included computational fluid dynamics analysis of components with implementation of salt properties into TRACE and system-level analyses with TRACE and RELAP5-3D.

Validating computer codes for specific analysis applications remains important and involves identifying and/or performing experimental work to generate validation data needed for code development and qualification activities. The University of California, Berkeley, in a partnership with ORNL, is working to create and document benchmark specifications and computer models for experiments performed at ORNL's MSRE in the 1960s. This project is funded by the DOE Nuclear Energy University Program (NEUP).

The SCALE code system is a widely used modeling and simulation suite for nuclear safety analysis and design that is developed, maintained, tested, and managed by ORNL. SCALE provides a comprehensive, verified and validated, user-friendly tool set for criticality safety, reactor physics, radiation shielding, radioactive source term characterization, and sensitivity and uncertainty analysis.

Because of the variety of potential salt and material combinations (including the evolution of fuel salts), there may be isotopes for which there are both large uncertainties in nuclear cross sections and high 
sensitivity of a cross section to a reactor's performance. This combined sensitivity/uncertainty may present serious performance and safety uncertainty. Accurate, verified data that can be used in nuclear code systems, such as SCALE, can typically be generated in about 2 years. However, reasonably accurate preliminary cross section estimates may be needed sooner, and they can potentially be generated using emerging molecular dynamics modeling techniques. DOE should support an assessment of existing data and cross section estimation techniques, and a prioritization of cross section data needs is required. Confirmatory data would be generated for cases in which uncertainty significantly impacts performance or safety aspects of a design that has a high probability of being commercialized.

The PARCS code solves spatial kinetics problems encompassing a wide range of physical phenomena such as neutron transport and the generation and decay of neutron precursors. Specifically, PARCS solves the time-dependent two-group neutron diffusion equation in three-dimensional Cartesian geometry using nodal methods to obtain the transient neutron flux distribution. PARCS is developed, maintained, tested, and managed by Purdue University.

TRACE is NRC's primary thermal-hydraulics analysis tool. The code is able to model thermal-hydraulic phenomena in both one-dimensional (1D) and three-dimensional (3D) space. Models used include multidimensional two-phase flow, nonequilibrium thermodynamics, generalized heat transfer, reflood, level tracking, and reactor kinetics.

RELAP5 has the capability to model thermal-hydraulic phenomena in 1D volumes. While this code still enjoys widespread use in the nuclear community, active maintenance will be phased out in the next few years as usage of TRACE grows.

Significant ongoing work is required to update, validate, and verify salt-fueled MSR codes for core physics and thermal-hydraulics to support licensing. NRC staff notes in the IAP document that significant efforts should be expected in development of thermal-fluid codes suitable for MSRs in which the fuel is in solution and transported by the coolant.

Task 5.1.1 - Develop Salt-fueled MSR Codes: Core heat removal is a significant branch in the licensing tree depicted in Figure 2. Development of an analytical capability for an MSR will likely require coupling between a thermal-fluids code and a neutronics code to simultaneously simulate the power, temperature, and velocity profile within the fuel/coolant mixture. The effort related to TRACE will be supported by NRC, but support for other codes will likely need to come from DOE. A gap analysis needs to be performed to determine the codes that are applicable to salt-fueled MSRs, determine required changes in existing codes, and identify new codes that address the unique features of an MSR. This will support modeling and simulation of salt-fueled MSR normal and accident conditions.

Task 5.1.2 - Develop FHR Codes: Because an FHR uses solid fuel, many existing codes may be applicable. However, with heat transfer to a molten salt, a gap analysis needs to be performed to determine the codes that are applicable to FHRs, determine required changes in existing codes, and identify new codes that address the unique features of an FHR. This will support modeling and simulation of FHR normal and accident conditions.

\subsection{HEAT REMOVAL SYSTEM TESTING}

The NRC IAP notes that code development is highly dependent on $\mathrm{V} \& \mathrm{~V}$, collectively known as assessment. Codes must be thoroughly assessed against applicable data to ensure that predictions of a hypothetical accident scenario are accurate for a full-scale plant. Because experimental data at full-reactor design scale is generally not available, code developers must utilize two types of tests-separate effects tests, which examine specific phenomena, and integral effects tests, which provide information on system performance. Both types of tests must be appropriately scaled to conditions expected in the full-scale plant, both geometrically and in the thermal-fluids range of conditions. Thus, access to well-scaled, applicable experimental data is central to the code development and assessment process discussed in 
Section 5.1. In an MSR, heat removal needs to account for all the varied locations where decay heat is produced.

Technical maturation for individual MSR designs will require further development by vendors prior to serious licensing discussion with NRC staff. DOE can support these vendors by providing the necessary tools to engineer and validate designs. The areas detailed below should be a high R\&D priority for MSR development and should be focused more at the system level for validating and demonstrating key aspects of MSR designs.

Manufacturing/operation capabilities: Reestablish the technologies to handle, purify, and continuously operate reactor-scale molten salt components.

Heat transport system: Demonstrate the performance of the secondary heat exchangers that transfer the reactor's energy from a low-pressure salt to a high-pressure fluid, which was not a part of the earlier MSRE program.

Direct reactor auxiliary cooling system (DRACS): Demonstrate the critical ability to reject decay heat to the local environment through natural circulation without vessel damage under loss-of-forcedcirculation conditions.

Task 5.2.1 - MSR System Tests: To support the heat removal R\&D needs listed in Section 5.2, numerous simulant test loops should be developed, including the following.

Forced-flow test loops: Life cycle behavior of fission products and other isotopes produced during operation depends on flow conditions within the reactor. Loops are needed to generate representative salt flow velocities at the temperatures of interest while in contact with candidate structural materials. Initially, these loops will be laboratory-scale experiments, but they will later evolve to engineering-scale demonstrations.

Component test loops: The manufacturing sector must be motivated to participate in the production of reactor components with the material combinations needed for MSRs. A program to encourage industry participation in the development of a non-nuclear salt test facility to test the components is needed. Because salt-to-salt heat exchangers are important to MSR deployment, eventually a two-loop salt test bed will be necessary. Two-loop systems allow for simultaneous testing of similar technologies (i.e., pumps) in separate test environments (primary and intermediate heat transfer systems).

Loops will provide data for use in models to design the next generation of more complex loops. Data from the new loops will validate performance of the models used to predict their behavior. Over the course of an iterative build-and-test activity, the necessary tools will be produced to evaluate candidate reactor concepts for licensing, along with the evidence necessary to justify their use. The tools and the experts using them must mature along with the experimental program.

A single liquid-salt test loop (LSTL) recently completed initial operations at ORNL. The LSTL is a versatile facility for the development and demonstration of high-temperature fluoride-salt technology. It is made from a high-nickel alloy and operates at up to $700^{\circ} \mathrm{C}$. The major components include a centrifugal pump to circulate the salt, a salt-to-air heat exchanger, three tanks, pressure control and trace heating systems, and associated instrumentation. The LSTL is available to develop and demonstrate technology for high-temperature fluoride-salt systems. The salt used in the initial operations was FLiNaK, and the loop has a total loop volume of $75 \mathrm{~L}$ and a flow rate at $<4.5 \mathrm{~kg} / \mathrm{s}$. Other test loops will be required.

Significant DOE support is necessary for heat removal system testing. General research can be performed on MSR reactor passive heat removal, but specific designs will also require evaluation and may need confirmatory testing at a representative scale. 


\section{MATERIALS ANALYSIS}

The NRC reactor review process focuses on the structural materials associated with the numerous safetyrelated portions of the design. MSRs operate at high temperatures; therefore, the structural materials must meet safety and performance requirements for high-temperature applications. Materials for existing reactors, operating at lower temperatures and higher pressures, achieve this by complying with the nuclear power section (Section III) of the American Society of Mechanical Engineers (ASME) Boiler and Pressure Vessel Code (BPVC). However, to date, NRC has not endorsed compliance with the hightemperature portion of the BPVC as an adequate indication of compliance with its safety requirements. Moreover, the BPVC does not address the effects of environmental stressors other than temperature (e.g., chemical corrosion or radiation damage). Of the five alloys approved for high-temperature nuclear construction in the proposed Section III, Division 5 of the BPVC, none are expected to have adequate corrosion resistance for MSRs for typical reactor lifetimes of 40-60 years without corrosion protection measures. Unfortunately, materials currently qualified or being qualified for use in other advanced reactors have limited application in direct contact with the salts of interest due to higher corrosion rates or operating temperatures. BPVC development, advanced materials development, and anticipated material lifetimes are all subject to NRC review.

Topic areas include materials behavior at time and temperature, irradiation damage, and salt compatibility. ASME codes need to reflect all these conditions in future nuclear code structure. The DOE MSR development program should stress the development of appropriate codes and code cases. Licensing input interfaces include structural analysis, fuel salt system boundary, and containment. Aspects of the current NRC review of materials are included in NUREG-0800, Chapter 3, "Design of Structures, Components, Equipment, and Systems”; Chapter 5, "Reactor Coolant System and Connected Systems”; Chapter 6, "Engineered Safety Features”; and Chapter 17, "Quality Assurance.”

\subsection{IRRADIATION AND PROPERTY TESTING}

Candidate materials for use in an MSR will require significant testing of properties and an analysis of the effects of irradiation. Example materials are discussed below.

Alloy N, also known as Hastelloy N or INOR-8, is a nickel-based alloy containing Mo, Cr, Fe, C, and small amounts of several other elements. Alloy $\mathrm{N}$ was developed at ORNL specifically for structural applications in salt-fueled MSRs with fluoride salt systems. Alloy $\mathrm{N}$ is also under consideration for use in FHRs. Alloy $\mathrm{N}$ has very good corrosion resistance to molten fluoride salts and good oxidation resistance in air environment and may be used for continuous operations at temperatures up to $982^{\circ} \mathrm{C}$. The maximum allowable stress for Alloy $\mathrm{N}$ decreases rapidly above $600^{\circ} \mathrm{C}$, becoming too low for practical use above $700^{\circ} \mathrm{C}$. Compared to the leading candidate materials that are usually considered for hightemperature nuclear reactor construction, the high-temperature strength of Alloy $\mathrm{N}$ is noticeably weaker. Alloy N may be considered for a lining on a higher strength material such as Alloy $800 \mathrm{H}$ or SS316 stainless steel. INL and ANL released a status report ${ }^{13}$ on MSR structural materials in May 2018 (INL/EXT-18-45171),

FHRs will make extensive use of continuous fiber ceramic composites (CFCCs) for reactor vessel internal components. Both $\mathrm{SiC}$ and carbon are known to be chemically compatible with fluoride salts. However, the primary coolant will inevitably include impurities, and the CFCCs may include both impurities and binder materials. Demonstrating the chemical compatibility of the primary coolant with production-grade CFCCs will be necessary. FHRs do not have a severe oxidation DBA and are intended to be operated with a somewhat reducing primary coolant chemical environment.

A DOE-sponsored materials quality roadmap effort is currently under way. Separate materials-related tasks are not listed here. 


\subsection{CODES AND STANDARDS DEVELOPMENT}

Consistent with OMB Circular A119, NRC uses voluntary consensus codes and standards in their regulations, as required by law. This provides cost savings to the regulator and industry, improves efficiency and transparency, increases safety, and maintains the high technical quality of regulatory requirements. As such, codes and standards development significantly influences the review process. A recent survey conducted by DOE for sodium fast reactor technology indicated that many codes and standards will require revision or development. The expectation is that MSRs will require even more revision and development. The structural materials report, INL/EXT-18-45171, ${ }^{13}$ touches on this subject.

No molten salt-compatible structural alloys are fully qualified for use. Both monolithic and clad alloy approaches are possible for MSRs, but neither is fully proven. The properties and in-core performance of chloride-based salts are much less well known than those of fluoride salts. Similarly, the processes to remove undesirable impurities such as sulfur and oxygen from chloride fuel salts are less well known than those for fluoride salts. Therefore, high-temperature structural and functional materials in contact with the MSR fuel salt system could be a schedule-limiting element for near-term MSR deployment. MSR material selection and qualification options include ${ }^{14}$ the following.

- Use code-qualified materials with known design methodologies and determine corrosion and irradiation allowances specific to MSR coolants and conditions. This includes the possibility of operating components for limited lifetimes and planning for component replacement.

- Use a corrosion-resistant protective cladding or coating over an existing code-approved alloy.

- Use code-qualifying known alloys (e.g., Alloy-N) for which there is a body of existing supporting data and determine the corrosion and irradiation allowances for specific contacting coolants and conditions.

- Slightly modify a known alloy (e.g., Alloy-N) to improve its performance, qualify it, and determine corrosion and irradiation allowances specific to contacting coolants and conditions.

- Qualify an entirely new material for service.

- Qualify material fabrication and joining technologies for existing materials. (Brazing may be used more extensively in high-temperature, low-pressure systems, but it is not currently addressed in the code.)

The structural material that has shown successful (yet limited) demonstration in MSR service is Alloy- $\mathrm{N}$ at the MSRE. Alloy-N was used for MSRE vessel and piping. It exhibited a corrosion rate sufficiently low that it can be considered for use in multi-decade component designs using fluoride salts. The neutron flux to the vessel wall was a more severe limit in the MSRE design. Both thermal and fast neutrons transmute nickel and lead to embrittlement. The loss of ductility typically reduces the system's ability to respond to transients later in life. Most modern MSR designs incorporate interior shielding to reduce the neutron fluence and consequently mitigate the loss of vessel ductility.

Alloy-N is not currently a code-qualified alloy for high-temperature use in a reactor system. However, based on a considerable body of data that can be credited toward qualification, Alloy- $\mathrm{N}$ is considered the monolithic structural alloy with the shortest pathway to a code qualification case for MSRs. A modified version of Alloy- $\mathrm{N}$ was studied after the MSRE to address observed fission product interactions. The activity to qualify a modified version of Alloy- $\mathrm{N}$ is expected to cost more than Alloy-N qualification because of the lack of existing data and uncertainty regarding how much credit can be taken for the Alloy-N data. DOE should support the investigation of the time and cost that would be required to complete the qualification of candidate monolithic alloys.

Using approved materials for structural strength in conjunction with a protective layer of compatible material (typically nickel or high-nickel alloys) is an option to develop near-term structural alloys for 
MSRs. DOE should support development and qualification of methods to coat or clad materials and fabricate components in a manner that ensures adequate corrosion protection.

Protective cladding over approved materials potentially offers lower costs and shorter development times to approved material and salt combinations compared to monolithic structural material qualification. ASME does not currently have complete design rules for bimetallic structures operating in the elevated temperature range where differential creep and fatigue induced by thermal expansion are issues. Therefore, these design rules would need to be developed. DOE should support the development, demonstration, and code approval of fabrication methodologies and associated design rules.

A related, alternative near-term strategy is to qualify structural materials for a more limited lifetime to permit near-term reactor construction and operation. This would allow for needed operational experience and would provide confirmatory materials data for extended use.

Graphite may be used for moderation, as a matrix for particle fuel or for structural support within an MSR core. It has generally been shown to have excellent chemical compatibility with fluoride salts; it shows little surface cracking; and it limits salt absorption and retention. However, the mechanical properties of graphite are damaged by neutron fluence, which results in limited lifetimes. Graphites used in the MSRE do not meet modern specifications of nuclear graphite and are of limited value toward qualification. DOE should support qualification of modern grades of graphite for salt service.

Lower-cost manufacturing methods will be needed to produce large components for advanced reactors, including MSRs. In today's electric market, this is essential to driving down the capital cost of nuclear power. The ability to repair and replace failed components may also allow better economic performance over a plant's lifetime and may reduce the financial risk from unexpected failures of a component intended for the plant's lifetime service. Manufacturing methods of interest include brazing, advanced, automated welding (preferably in air), and near-net-shape additive manufacturing techniques.

Components of interest include reactor vessels, large tanks, heat exchangers, and piping sections.

ANS 20.1, "Nuclear Safety Criteria and Design Process for Fluoride Salt-Cooled High-Temperature Reactor Nuclear Power Plants," and ANS-20.2, "Nuclear Safety Design Criteria and Functional Performance Requirements for Liquid-Fuel Molten-Salt Reactor Nuclear Power Plants,” are the current focus for MSRs, but the need for many codes and standards may result from these ANS standards, including such topics as

- $\quad$ salt valves (freeze valves, containment isolation valves, etc.),

- concrete standards,

- instrumentation,

- environmental qualification,

- materials, and

- components.

Task 6.2.1 - MSR Codes and Standards Development: A gap analysis needs to be performed to determine the codes and standards that are applicable to MSRs, determine required changes in existing codes and standards, and identify new codes and standards that address the unique features of an MSR. This will help focus material R\&D on appropriate MSR applications. In addition, codes and standards for advanced reactors are being discussed in several venues. DOE should ensure that MSR technology is supported in all venues to evaluate stakeholder priorities. DOE should advocate for MSR codes and standards and interact with NRC in this process to incorporate voluntary consensus codes and standards into their regulations. This will simplify and expedite regulatory review for future applications. 


\section{ANALYTICAL CODES AND METHODS}

MSRs include fast and thermal neutron spectrum reactors with chloride or fluoride salts as coolants. The potential objectives of MSR technologies include high-efficiency electricity generation, high-temperature process heat, implementation of a sustainable nuclear fuel cycle, or development of a new test reactor capability. Modeling and simulation capabilities are needed to support the development of these concepts, including design tools and safety evaluation tools.

Accident codes do not exist for salt-fueled MSRs. This area will require significant DOE/NRC developmental effort, including V\&V. Licensing input interfaces include accident sequences, PRA, core heat removal, fission product transport, mechanistic source term, and fuel qualification. Aspects of the current NRC review of codes and methods are included in NUREG-0800, Chapter 15, "Transient and Accident Analysis.”

\subsection{DEVELOP REQUIRED METHODS AND DATA}

Modeling and simulation is a key factor for advanced reactor design and licensing. A broad set of analysis tools is available to analyze performance and make design decisions, but these tools must be adapted and validated for use with salt reactors to support licensing review. This includes a comprehensive functional needs assessment of the leading MSR concepts, such as thermal reactors with fluoride salts and fast reactors using chloride salts. This assessment would require identification and prioritization of user needs; coordination of outreach to DOE national laboratory, university, and industry experts; a comprehensive overview of assumptions on reactors and fuels of interest; and collaboration.

The data needed for these analyses are limited in several important areas. DOE will need to support gathering the data needed for MSR modeling and simulation. Data could be produced using separate effects tests, integrated effects tests, and test reactors. Examples of such data include salt properties of the desired salts for thermal performance and chemistry, the behavior of tritium, fission products and actinides within the system including migration and deposition, materials data for structural and moderator materials, and nuclear data for neutronics simulations.

Task 7.1.1 - Develop MSR Performance Models: A licensing challenge (Figure 2) for MSR development is the development of integrated performance models that can be used for reactor concept performance validation and licensing. To meet this challenge, the following capabilities are needed for each concept under consideration.

1. Identification of start-up core salt compositions

2. Core neutronic evaluation, including precursor drift models that account for delayed neutron production throughout the primary loop and their reintroduction into the core

3. Radionuclide inventory accounting including source term production, holdup and release mechanism models for specific materials and operating conditions, and appropriate salt solubility and thermo-physical property models

4. Thermal-hydraulic analyses of sufficient fidelity to capture flow and power dynamics in saltfueled concepts, including the use of computational fluid dynamics codes to evaluate open core concepts

5. Time-, temperature-, flux-, and flow-dependent materials and salt interaction data and models to predict corrosion, erosion, and irradiation effects

6. Dynamic reactor system models that include primary system isotope transport and constituent holdup and release mechanisms

This task is related to Tasks 5.1.1 and 5.1.2. 


\subsection{VALIDATE CODES AND MODELS}

Significant testing will be needed to validate the models. It is essential that DOE also support data validation. This is a wide area, encompassing everything from fundamental constitutive relationships to integral benchmarks for reactor physics, thermal-hydraulics, materials, and chemistry simulations. Overall, the scope of the modeling and simulation capabilities for MSRs is like other reactors types. However, one area that is unique to salt-fueled MSRs is the convection of delayed neutron precursors and the transit times of the fuel through the core and the remainder of the primary loop. The effect of fuel circulation through the core region, known as delayed neutron precursor drift or convection, must be quantified, as well as the associated impact on the neutron balance and flux-energy spectrum of the proposed system.

Once reactor performance models are developed, including $V \& V$, they can be used to evaluate and optimize system performance and behavior. Transient models will simulate decades of normal reactor history and then follow reactor performance through anticipated transient events, eventually including severe accident scenarios. These models will eventually predict radioactive inventory behavior during accident scenarios that will inform the licensing process.

Modeling and simulation tools must be developed for design, analysis, and licensing. NRC uses established language, processes, and approved methods and tools to evaluate a reactor for licensing. Two types of tools are used in licensing - confirmatory tools, used by NRC staff to confirm submitted results, and licensing tools, developed and used by the applicant to gain approval of analyses. Licensees may develop and use their own tools, which are subject to significant oversight for QA and V\&V. DOE can provide capabilities in modeling and simulation that meet QA and V\&V requirements, and those capabilities can later be adopted for use by either NRC or by vendors.

Task 7.2.1 - MSR Code Validation: Validating computer codes for MSR applications remains important and involves code validation and experimental work to generate validation data needed for code development and qualification activities. DOE should support development of a detailed modeling roadmap to identify long-term modeling and simulation needs and the near-term R\&D activities to meet them. 


\section{INSTRUMENTATION AND CONTROL}

The ability to operate a reactor depends on the development of robust and reliable reactor components, technology, and operating systems. Technology to allow simple and straightforward operations and the ability to maintain operating systems is critical to successful deployment and operation. This includes consideration of high-temperature operation in high-dose regions.

Salt-fueled MSRs will have higher radiation levels throughout the primary system than other reactor concepts and will likely require radiation-tolerant components and/or readily replaceable components. Instrumentation needs related to onsite, in situ salt operation (including safeguards monitoring) have not yet been completely identified or developed. Additionally, instrumentation related to remote inspection and maintenance requires definition and development. The need for remote inspection and operations is concept dependent and will occur as designs become more detailed. Radiation hardening of measurement, vision, and manipulation systems will be required. Cyber-security planning is also a licensing consideration.

Therefore, as depicted in the licensing tree (Figure 2), MSRs will need new instrumentation and control (I\&C) techniques for measuring the standard variables needed for licensing and safety. Licensing input interfaces for I\&C include all areas discussed in this roadmap. Aspects of the current NRC review of I\&C are included in NUREG-0800, Chapter 7, "Instrumentation and Controls"; Chapter 15, "Transient and Accident Analysis"; and Chapter 18, "Human Factors Engineering."

\subsection{SENSORS AND CONTROLS}

As with any nuclear power plant, the overall function of the MSR instrumentation system is to provide the information necessary to safely and efficiently operate the plant over its entire lifetime under the full range of conditions it may experience. Measurements include process conditions (both online and during outages), component health, and accident progression monitoring.

Instrumentation to measure fuel-salt chemical and physical properties online is not currently available. Performing measurements in the high-temperature, high-flow molten salt environment is technically challenging because the near-fuel radiation levels exceed the capabilities of current solid-state electronics. However, MSRs can likely be controlled using common measurement and control techniques if sensors are modified for higher temperatures and the potential for salt contact. Associated electronics may also need to be remotely located in shielded or low-radiation areas. Thus, the instrumentation needed to control MSRs is largely considered to be an adaptation of existing technology as opposed to a new development activity. This includes the following basic reactor measurement functions:

- neutron flux,

- temperature,

- pressure,

- flow,

- levels, and

- redox condition.

Neutron flux measurement instruments for advanced reactors (up to $\sim 700^{\circ} \mathrm{C}$ ), including MSRs, are currently under development and are scheduled for demonstration and transfer to industry within the next few years. Drift-free first-principle thermometry has been under development for several years and is nearing the point where it can be transferred to industry as well. No additional activity is currently planned in this area. Pressure sensors can be configured to directly measure pressure or pressure 
differentials for level and flow detection. Either configuration may be able to use extension ports to place sensitive instrumentation in lower temperature and radiation environments.

Specific MSR instrumentation technology requirements derive from their performance requirements. For example, the required accuracy and response time of FHR primary loop temperature and mass flow measurement arise from the need to know the thermal power generation rate, facilitating efficient power cycle operation, providing assurance of core cooling, and enabling calibration of the neutron-based power measurements. A thorough understanding of MSR performance requirements is thus necessary to establish technology requirements. A DOE-sponsored report ${ }^{15}$ on I\&C framework development for MSR technologies was released by ORNL in June 2018 (ORNL/TM-2018/868).

Task 8.1.1 - MSR Sensors and Controls: Research should be conducted on sensors and controls that can withstand the severe environments encountered in MSR designs as identified by industry and necessary to support the plant licensing basis. Safety-related instrumentation should be simplified to the extent possible to provide the highest possible assurance of reliable, safe operation while minimizing equipment qualification challenges.

\subsection{SURVEILLANCE AND DIAGNOSTICS}

Salt, fission product, and corrosion monitoring instrumentation will be required for MSRs. This could include monitoring for unexpected material corrosion or for the detection of specific problematic salt characteristics that could lead to enhanced material degradation. Online diagnostics are not yet possible and would require salt sampling for off-line analysis. Consequently, specialized salt measurement technology, as opposed to classical physical process sensors, is the likely diagnostic development need for MSRs. Instrumentation for safeguards inspection and radionuclide tracking will also require development.

The salts are highly corrosive, and salt-fueled MSRs tend to operate under high-flow conditions. There is low potential for loose parts in the core and for salt boundary leakage. The operational intent is to maintain redox control based on sampling. However, loose parts monitoring and leakage detection will be important diagnostic tools for MSRs.

Task 8.2.1 - MSR Surveillance and Diagnostics: Analyses should be conducted to identify technology gaps related to loose-part monitoring, sampling procedures, small sample tubing, flanges, and leak detection. This will directly support R\&D associated with these specific diagnostic issues. This ultimately will support the establishment of Technical Specifications related to sampling and leakage detection.

\subsection{HUMAN FACTORS}

Unlike LWRs, MSRs have no known accident scenarios that require a rapid response. The high likelihood for the lack of a requirement for rapid response derives from the combination of the lower core power density, the large thermal mass in vessel, the large margin to boiling, and the high tolerance of core temperature rise. All known reactivity insertion and loss-of-core-coolability accidents progress slowly. MSRs have no mechanisms to overpressure the primary coolant boundary.

While general design principles such as high quality, diversity, and defense-in-depth remain requirements for any reactor, the lack of a pressure differential to disperse radionuclides and the much larger time and temperature margins inherently afforded by an MSR to respond to any accident may alter the manmachine interface for an MSR. These factors may alter the instrumentation required, alter the safety response from the equipment, and affect the allocation of responsibility for a safety response from an operator. The need to rely on remote operations for maintenance and surveillance activities may mean there is less automation in MSRs than in other advanced reactor technologies. The split between man and machine needs to be considered by DOE/NRC. Passive safety becomes an essential consideration. DOE should support human factors programs for MSR technology. 
The longer response times afforded for communication means that no obvious imperative exists for sensor signals to have direct point-to-point wiring. Indeed, the timing requirements for an MSR's digital communications network can be significantly relaxed compared with those for an LWR. Given the large time (days) for accident response at an MSR, the passive nature of the safety response functions, and the ability to manually perform safety system actuation in the event of simultaneous communication and passive safety system actuation failure, separating the digital control network from the safety network may no longer be necessary. The continuous use of the control network provides online, albeit limited, functionality and end-to-end testing of the communications network. This may result in a higher reliability automatic system, while the manual backup provides the defense-in-depth ordinarily provided by the separation of the control and safety systems.

Task 8.3.1 - MSR Human Factors: A gap analysis needs to be performed on MSR communication requirements, man-machine interface requirements, and autonomous control requirements. Investigate the need for remote operations to conduct surveillances and equipment maintenance. 


\section{STRUCTURAL ANALYSIS}

DOE needs good data to validate structural models in extreme environments, including high-radiation, high-temperature, and corrosive materials. Adequate seismic support and isolation are also licensing issues, as are other external stresses such as wind, precipitation, flooding, and aircraft hazards. Immediate components of interest include steel-lined containments, drip pans, reactor vessels, large tanks, heat exchangers, and piping sections. Consideration of extended systems that include radionuclides is likewise important.

This licensing input interfaces with the materials analysis and analytical codes licensing inputs. Aspects of the current NRC review of structural analysis are included in NUREG-0800, Chapter 3, "Design of Structures, Components, Equipment, and Systems,” and individual system chapters.

\section{$9.1 \quad$ STRUCTURAL TESTS}

The MSR structural analyses can start by designing and building a series of loops, beginning with singlepurpose loops and evolving to reactor-scale component testing. This will allow for the structural analysis of fabrication methods and chemistry under relevant operating conditions (passive and forced-flow) at representative high temperatures and low pressures using a variety of salt and structural material combinations. This will demonstrate structural performance through testing and is essential in obtaining full NRC approval.

Loops will provide data for use in models to design the next generation of more complex loops. Data from the new loops will validate performance of the models used to predict their behavior. Over the course of an iterative build-and-test activity, the necessary tools will be produced to evaluate candidate reactor concepts for licensing (Figure 2), along with the evidence necessary to justify their use. The tools and the experts using them must mature along with the experimental program.

Task 9.1.1 - MSR Loop Tests: A conceptual progression of single-purpose loops evolving to reactorscale component testing for the study of fabrication methods, chemistry, and structural integrity under relevant operating conditions includes the following.

1. Develop the capability to produce, process (clean), and characterize salts.

2. Establish natural circulation harp loops at representative temperatures using a variety of salt and structural material combinations.

3. Create forced-flow (pumped) loops to create representative flow and temperature conditions.

4. Develop larger separate-effects loops to study specific MSR issues and to test mitigating strategies for issues such as tritium production and fission product life cycle.

5. Conduct an engineering-scale demonstration of components and system operation and management.

6. Conduct reactor-scale component loop testing.

\subsection{REMOTE OPERATIONS}

Components in salt-fueled MSRs will become highly radioactive with reactor operation due to their proximity to or contact with the fuel salt. As a result, inspection, maintenance, and recovery events (spilled fuel sample, dropped maintenance item, etc.) will require considerable forethought as an aspect of the design. Workers must be able to perform these functions from a distance to ensure their safety. The ability to inspect safety-related plant components will be a licensing requirement and will generally be 
included as plant Technical Specifications. Maintenance will be a necessary part of normal plant operations.

Task 9.2.1 - Salt-fueled MSR Remote Maintenance: Analyses should be conducted to determine best practices for remote maintenance, inspection, and recovery operations to support the ability to meet Technical Specifications and Operations programs. Such analyses could lead to R\&D for maintenance and inspection mockups using long-handled tools, digital tools, and other remote inspection technologies. This task is related to Task 8.3.1. 


\section{SITE BOUNDARY}

As depicted in the licensing tree trunk shown in Figure 2, dose calculations involving the health and safety of the public are a driving consideration for licensing. Licensing factors that impact site boundary analysis include the MSR fuel salt, the disposition of the fission products that are generated, the fuel salt system boundary, the leak-tight or functional containment design, and the mechanistic source term. Aspects of the current NRC review of public health and safety and protection of the environment are included in NUREG-0800, Chapter 2, "Site Characteristics and Site Parameters"; Chapter 4, "Reactor"; Chapter 6, "Engineered Safety Features”; Chapter 9, "Auxiliary Systems”; Chapter 11, "Radioactive Waste Management”; Chapter 12, "Radiation Protection”; and Chapter 15, "Transient and Accident Analysis.”

\subsection{FUEL}

The behavior of the MSR fuel under normal operations, AOOs, postulated accidents, and severe accidents needs to be modeled and understood. Fuel storage, especially liquid fuel, is also a licensing consideration including a safe means to transfer fuel to and from the reactor and maintaining the fuel outside the core in a subcritical configuration. DOE and NRC will need data to validate models. The role of the fuel needs to be fully understood with respect to fission product retention, transport, etc. NRC will need to revise regulatory documents accordingly. This is largely covered under fuel qualification. However, additional discussion in this section includes phenomena identification and safeguards.

The fuel licensing input interfaces with fuel qualification, analytical codes and methods, materials analysis, core heat removal (fuel is the coolant), and containment.

\subsubsection{Phenomena Identification}

MSRs have limited operational experience, and that experience is limited to power levels below 10 megawatts thermal. Although the limited operational experience indicates that MSRs have strong negative reactivity feedback, reactor power instability or reactivity increases must be fully evaluated to support required accident analyses. This can potentially be accomplished through the use of multi-physics simulation and visualization tools recently developed to examine LWRs, but adaptation to MSRs is required. It is important that DOE support investigations into the possibility of encountering new operational phenomena that could limit MSR performance or produce unsafe operational states as reactor sizes are scaled larger.

NRC notes in its advanced reactor IAP, the LWR fuel performance analysis code suite used by the staff, FRAPCON and FRAPTRAN, are not currently able to analyze MSR fuel, and they would require extensive redevelopment to achieve this functionality. For FHRs, an existing fuel code might be applicable. For MSRs, NRC is not aware of codes already developed to analyze fuel performance. Developing a code to analyze fuel performance for dissolved fuel will be a multidiscipline effort, likely requiring computational fluid dynamics with coupled kinetics and models to account for changes in fuel composition. In order to develop the capability to perform fuel performance analysis of MSRs, NRC would need to (1) develop in-depth knowledge of fuel design, fuel functional requirements, and fuel characteristics critical to safety and accident performance, (2) develop a new fuel performance analysis code, and (3) identify experimental data needs and complete an independent code assessment. In addition, fuel simulation codes would need to be developed and benchmark experiments planned and executed all under an NQA 1 program. While NRC will adapt their codes as necessary, DOE should consider supporting individual vendors in this area to expedite the eventual licensing process. 


\subsubsection{Safeguards}

NRC staff will consider safeguards as part of a licensing review. Current LWR technology ensures material control and accountability by verifying the presence of discrete items of special nuclear material, such as fuel, and other objects containing special nuclear material, such as detectors. While an FHR will likely be able to employ similar techniques, salt-fueled MSRs will not because the material of interest is dissolved into the salt and isotopes are continuously being consumed and created. Additionally, on-line fuel salt processing could potentially provide pathways for the removal of nuclear materials.

It will be problematic to introduce safeguards after the design of an MSR is complete because the necessary measurement instrumentation is integral to the plant. MSR technology includes a tightly coupled reactor and fuel cycle operations housed in a single facility. These unique aspects of MSRs will require (1) R\&D for new safeguards technologies and (2) evaluation of new applications of current safeguards technologies that can meet these challenges. Factors influencing MSR safeguards include

- the homogeneous mixture of fuel, coolant, fission products, and actinides;

- continuous variation of isotopic concentrations in the fuel salt, including removal (passive or active) of fission products, rare earth elements, and noble metals;

- $\quad$ high melting temperature;

- unique refueling schemes, including the ability to continuously feed the core with fresh fissile or fertile material;

- the presence of solid (frozen) fuel, potentially requiring a different safeguards process from that required for the liquid fuel; and

- the presence of fuel outside the vessel.

Task 10.1.1 - Salt-fueled MSR Safeguards Assessment: A generic MSR safeguards needs assessment should be performed to describe typical safeguards objectives and methodologies, identify probable key measurement points and control areas within proposed designs, and describe the possible monitoring methods. This information will be used to identify gaps between anticipated needs and current measurement and will further identify needed R\&D to provide adequate safeguards monitoring capabilities.

Subsequently, design variants will require specific evaluation due to differences in salt process flows, salt fueling methods, salt cleanup technologies employed, the export control status of required technologies, and the deployment intent (i.e., domestic and/or international). Results of the needs assessment should explicitly consider and discuss reprocessing requirements and deployment strategies, as well as expectations for final waste forms and disposition strategies.

\subsection{FISSION PRODUCTS}

For MSRs, DOE and NRC need to understand what fission products are produced, the quantity that is produced, where the fission products are located, and the timing. In addition, DOE and NRC will need to understand what approach individual vendors are taking for fuel salt chemistry control, cleanup methods, etc.

After a period of operation, salt-fueled MSRs will include gaseous, soluble, and nonsoluble fission products. The nonsoluble fission products will plate out in various locations within the fuel salt system boundary. The gaseous fission products will likely be swept from the system and held for decay in an offgas system. Some designs may opt to further polish or filter the soluble fission products in the fuel salt by some mechanical or chemical means. The treatment and handling of fission products in the MSR fuel salt and the description of this process must be very precise to avoid the waste treatment facility being 
construed as a colocated special nuclear material fuel cycle facility. DOE should support further investigation into fission product transport, disposition, cleanup, and polishing to support the licensing review. Existing release path tools provide a starting point for analysis, but transport and deposition models will need revision to accommodate new MSR fission product release pathways. Beryllium release also needs to be considered if it is used in the MSR design. Radiation protection throughout a salt-fueled MSR will be a licensing consideration.

The fission product licensing input interfaces with fission product transport, fuel qualification, analytical codes and methods, core heat removal, mechanistic source terms, and containment.

Task 10.2.1 - Salt-fueled MSR Fission Product Analysis: Analyses into the development of radiation protection design features should be conducted based on fission product transport, disposition (plate-out), cleanup, and polishing. This directly supports the analysis of source terms.

\subsection{FUEL SALT SYSTEM BOUNDARY}

Maintaining the integrity of the primary coolant boundary is both a capital asset preservation measurement and part of the reactor safety case. DOE and NRC need to understand the function and the extent of the boundary beyond the vessel and piping (gas cleanup, drain tanks, polishing and/or processing systems, etc.) and the barrier it provides to limit radionuclide release. NRC needs to reflect the boundary role in regulatory documents.

The fuel salt system boundary licensing input interfaces with fuel, containment, structural analysis, materials analysis, and core heat removal.

\subsubsection{Salt Science}

Corrosion and chemistry control are key licensing issues with regard to the fuel salt system boundary integrity. This is a complicated issue because transmutation of salt constituents in-core (producing actinides, tritium, and other radioactive isotopes) and fission product generation in fuel salts will cause the salts themselves to change throughout use. Fuel salts, therefore, present additional challenges for corrosion control. However, the disadvantage of these challenges can potentially be offset by the ability to monitor and manipulate salt composition during reactor operation.

The corrosion technology for fluoride salts is at an advanced stage of development. An extensive corrosion program has been conducted with several families of fluoride mixtures using both commercial and developmental high-temperature alloys. Several current MSR developers are planning to use fluoride data from the extensive set of previous salt and material compatibility studies. However, existing data on salt and material corrosion and compatibility relevant to MSRs are insufficient to provide a good baseline for a body of knowledge relevant to chloride salt-fueled reactor concepts. DOE should support the collection of corrosion data for various candidate salt and material combinations. Focused data collection on chloride salts should be included.

Obtaining the necessary data will require implementation of structured and efficient methods to study the impacts of varying chemistry on corrosion rates under various temperature, velocity, and eventually, irradiation environments. This will be done in conjunction with the loop testing discussed in Section 9.1.

The compatibility of salts with structural, moderating, and fuel materials must be demonstrated and understood within the context of its use. Corrosion mechanisms must be well understood and demonstrated for the normal conditions at which the reactor operates most of the time. However, the short-term response of salts during temporary off-normal conditions must also be understood for licensing because it can dictate the peak performance requirements for reactor monitoring, processing, and safety systems. 
In addition to general corrosion, certain types of corrosion specific to molten salt systems must be considered. These include the following:

1. chemically and thermally induced mass transport of specific species from the alloy system due to changes in alloy component solubility in the salt at different temperatures,

2. the impact of multiple alloys within the system, including the deposition of corrosion products from one alloy onto another, or induced anodic effects due to different electric potentials, and

3. stress corrosion cracking related to fission product or other impurities in the molten salt.

Coolant salts are often used in heat transfer loops within MSRs. These salts can be similar in composition to the fuel salts, or they can be entirely different. Coolant salts usually must be compatible with multiple materials and must meet neutronic and irradiation requirements in addition to thermal-hydraulic and neutronic requirements. Corrosion and chemistry control data must be generated and evaluated for the coolant loop because of the potential for a coolant leak at the fuel salt-to-coolant salt heat exchanger.

Task 10.3.1 - MSR Salt Evaluations: Out-of-pile and in-pile tests for fluoride and chloride salts should be conducted. The purpose is to collect data on corrosion rates and proposed reactor materials to support understanding of salt corrosion mechanisms. The performance of the selected redox control method needs to be demonstrated in electrically heated salt loops to provide confidence that the protection system will perform as anticipated. Information on salt stability should also be documented. This directly supports material R\&D and barrier analyses.

\subsubsection{Component Development}

Numerous system components can impact the performance of the fuel-salt-system boundary and will be subject to licensing review. Each design will have unique needs and materials, but some common research areas will be of interest to all or most vendors. These include the following.

- Pumps: Molten salt pumps must be developed over a broad range of sizes and flow rates. This includes small-laboratory scale pumps for forced flow corrosion tests and salt behavior studies, for which the flow rates may be on the order of only a few liters per minute. Ultimately, however, pumps must be tested for primary flow loops for larger scale reactors. In an MSR, flow also impacts the distribution of delayed neutron precursors and, therefore, reactor power. DOE should support the evaluation of MSR pump technology because of the important role that flow plays in MSR reactor control.

- Heat exchangers: Heat exchangers are a key component regarding the integrity of the fuel salt system boundary. Evaluation of heat exchanger materials, claddings, and fabrication methods, especially joining methods, is required. Heat exchangers possibly represent the most complex components for which clad materials might be used. Thus, evaluating the ability to fabricate complex components, such as heat exchangers, using bimetallic materials is a high priority. Tritium transfer through heat exchangers will also be a licensing consideration.

- Valves: Generic valve development is a licensing consideration for the fuel-salt-system boundary. MSR boundary valves are intended to be used for multiple open/close cycles and to tolerate freeze-thaw cycles. Valve technology lends itself to testing on smaller test loops. Electrically actuated valve technologies that can be adapted to a number of material and salt combinations are a high priority for MSR development and licensing.

- Flange and seals: Reusable flanges and seals, as opposed to all-welded joints, are invaluable for component removal and replacement. This is especially true for MSRs, where remote maintenance will play an important role. Flanges can be tested on the smaller, existing forced flow loops. Flanges, like valves, are a high priority for MSR development and licensing. 
- Rupture disks: Rupture disks are the intermediate loop piping element intended to decouple any potential pressure excursions within the power cycle from the primary loop.

- Remote inspection and maintenance: Because of the operating environment, MSR inspection and maintenance will need to be performed remotely. DOE should support the development and demonstration of inspection and maintenance techniques for MSRs. An inspection program will be required for MSR Technical Specifications as a part of the licensing process.

Additional design-specific technology considerations of fuel-salt-system boundary include interfaces to reactivity control systems, decay heat removal systems, and normal heat transfer systems.

\subsection{CONTAINMENT}

Through the DOE-NRC joint initiative on advanced reactor design criteria, NRC has confirmed that the Commission previously concluded that a leak-tight containment structure is not required for modular HTGRs because these plants can demonstrate adequate protection of the public through other barrier configurations. Industry and DOE are now engaged in NRC interactions to establish how this concept can be applied to other advanced non-LWR technologies, including MSRs. NRC staff is currently developing a Commission paper on this topic ${ }^{16}$ and will be engaging with industry in 2018 to address and resolve this key policy topic. In its April 2018 meeting, the Advisory Committee on Reactor Safeguards supported a technology-neutral approach to functional containment with some recommendations. In June 2018, the NRC Executive Director for Operations acknowledged the committee review and noted that functional containment would be included in discussions on diversity and defense-in-depth related to the LMP.

Radionuclide containment is the primary reactor safety function fundamental to achieving NRC's safety goals. Development of appropriate performance criteria for design features serving to limit the release of radioactive materials is a central element of containment design and evaluation. The rationale for the LWR containment performance requirements arises from the physics of accident progression in LWRs. LWR loss-of-coolant accidents (LOCAs) can lead to catastrophic fuel damage, cascading to a substantial pressure challenge and possible failure of the outer containment building and eventually substantial release of radionuclides into the environment.

Salt-fueled MSRs operate at near-atmospheric pressure and, consequently, lack an equivalent accident to LWR large or small break LOCAs that could cause significant stress on the next layer of containment. The lack of cascading failure accident sequences enables MSRs to employ independent containment layers to provide defense-in-depth. Even massive failure of an MSR's fuel-salt boundary only results in fuel salt flowing out into the next layer of containment. Further, as liquid fuel is not vulnerable to structural damage, it retains its radionuclide retention properties following leaking out of the first layer of containment. Therefore, MSRs can continue to provide radionuclide retention following either massive or minor failure of their fuel-salt wetted boundary by employing additional boundary layers that are normally not salt wetted and subject to less radiation exposure. The lower safety consequences of fuel-salt boundary layer failure (as compared to LWR LOCAs) result in the ability to achieve "at least the same degree of protection of the environment and public health and safety ... that is required for current generation light-water reactors" 17 without requiring compliance with the highly prescriptive materials requirements embodied in Section III of the ASME BPVC.

Using a functional containment for salt-fueled MSR technologies would substantially broaden the range of possible materials, fabrication methods, and operating procedures. If functional containment is approved for MSRs, it would obviate the need to ASME BPVC Section III Division 5 qualification of its salt wetted boundary material. Further, functional containment could enable treating any particular layer of containment as a consumable component intended for periodic replacement (i.e., an MSR could be operated until its innermost containment layer fails, at which point the layer would be replaced as part of normal maintenance) rather than vital structures required for plant safety. 
The containment licensing input interfaces with fuel-salt-system boundary, fuel, core heat removal, structural analysis, materials analysis, fission product transport, mechanistic source term, and analytical codes and methods.

Task 10.4.1 - Develop Functional Containment Requirements for Salt-fueled MSRs: The analyses and code considerations necessary for MSRs to employ a functional containment process should be investigated. This will support materials $R \& D$ for the various functional containment barriers as well as source term evaluations and siting considerations.

Task 10.4.2 - Develop Storage Requirements for Salt-fueled MSR Components: Salt-fueled MSR components will become highly radioactive after reactor operation. An analysis of the storage requirements for replaced or residual parts should conducted. This will support materials R\&D and component maintenance R\&D.

Task 10.4.3 - Attributes of MSR Underground Siting: Many advanced reactors are considering a reactor building that is completely or partially below grade. A topical report should be prepared on the attributes of underground siting. This would include such considerations as seismic advantage, sourceterm retention, aircraft hazards, fire and flooding, security, control, and staff ingress and egress. Belowgrade siting is often touted as a licensing advantage, but no reference documentation exists. This would directly support materials $R \& D$, seismic $R \& D$, fission product transport, DBA modeling and simulation, and siting. 


\section{MECHANISTIC SOURCE TERM}

NRC has summarized a potential approach for establishing a consequence-based emergency planning zone for a reactor facility based on an evaluation of its risk to the public, rather than applying the prescriptive 10 and 50 mile zone sizes that have been applied to the large LWRs in the operating fleet. NRC has issued guidance for industry to pursue this approach and is now processing a formal change to current regulations, due to be completed and published in early 2020. In general, a salt-fueled MSR has a smaller source term than a solid-fueled reactor of similar thermal output because salt-fueled MSRs have low excess nuclear reactivity.

Key licensing questions require an understanding of MSR performance under a range of conditions and cover such topics as fission products; i.e., what is their distribution, what is the location of the source term, how will the short-lived fission products be cooled, and for what range of fission product accumulations do fluoride and chloride salts maintain appropriate thermo-hydraulic properties? Furthermore, for fast spectrum MSRs, are chloride salts radiolytically stable under in-pile conditions, what is the volatility of chlorine, and how significantly does intense fast flux accelerate degradation of clad structural material? In the operations area, can major components of MSRs be replaced effectively, and will natural circulation-based decay heat removal start up rapidly enough to prevent component damage in high-power-density MSRs? What is the risk that regulatory radiological release limits will be exceeded?

It should be noted that MSRs inherently have more benign responses to massive failure of their reactor vessel than other advanced reactors. MSR cores are in their most reactive configuration and lack substantial excess reactivity. Consequently, an MSR LOCA cannot result in a positive reactivity accident. Moreover, a massive failure of an MSR's coolant boundary does not result in significant pressure venting into the containment building nor can unconstrained exposure of an MSR's fuel (or coolant) to oxygen result in a pressure generating exothermic chemical reaction.

The MSRE employed a defense-in-depth approach to radionuclide containment. ${ }^{18}$ MSRE's safety analysis was based upon an evaluation of whether specific accidents would cause radionuclides to be released beyond the first level of containment. Additional containment layers were employed such that no credible accidents would result in releases to the public. Multiple simultaneous failures needed to be postulated to estimate a worst-case source term for licensing purposes as no identified single event could result in significant radionuclide release from the plant.

Work commissioned by the NRC is under way at SNL on the MSR mechanistic source term. DOE and NRC need to understand the functional behavior of all safety-related system interactions and the nature of reactor operations that combine to minimize the mechanistic source term.

The mechanistic source term licensing input interfaces with all licensing inputs to the system, especially the fuel, fission product transport, fuel-salt-system boundary, and containment licensing inputs.

Task 11.1 - MSR Mechanistic Source-Term Evaluation: To address the licensing questions related to source term, analyses addressing the key phenomenology associated with major MSR variants must be performed to identify generic MSR, and eventually design-specific accident event sequences. Radionuclide retention in molten salt needs to be evaluated. Information that must be identified to perform accurate accident analyses includes the following:

- $\quad$ salt properties under worst-case scenarios,

- radioactive inventories within a system, 
- holdup and release mechanism models for radioactive source terms, and

- technologies available to mitigate and manage radioactive material releases including engineered safety features.

Source-term analyses will support materials R\&D, functional containment analyses, radioactive shine mitigation, and siting considerations. 


\section{SUMMARY}

Developing confidence in the likelihood of MSRs to safely, reliably, and profitably operate is the single largest challenge to commercial deployment. The International Atomic Energy Agency (IAEA) Specific Safety Requirements SSR-2/1, “Safety of Nuclear Power Plants: Design,” defines the fundamental safety functions for nuclear reactors as follows.

Fulfilment of the following fundamental safety functions for a nuclear power plant shall be ensured for all plant states:

i. control of reactivity;

ii. removal of heat from the reactor and from the fuel store; and

iii. confinement of radioactive material, shielding against radiation and control of planned radioactive releases, as well as limitation of accidental radioactive releases.

US reactor licensing is focused specifically on protecting the health and safety of the public as embodied by the previous IAEA statement. Because of the nature of homogenous fuel, salt-fueled MSRs also require consideration of the regulation of associated non-reactor nuclear facilities that support MSR operation. Licensing activities will include reviews of operating procedures and programs.

This roadmap is intended to highlight R\&D needs to support MSR development and licensing. As a result, some licensing topics are not explicitly included. For example, operational staffing and security staffing are important advanced reactor issues that impact reactor licensing, safety, and operational economics. Staffing is not addressed in this roadmap. Likewise, emergency planning is not directly addressed in this roadmap, although source term is considered. However, NEI is actively addressing these generic licensing issues with industry and with NRC staff. Some of these ongoing efforts are summarized in Subsection 12.1.

\subsection{TRAJECTORY ISSUES UNDER CONSIDERATION BY THE NRC}

The NRC staff and other industry stakeholders are working to streamline the advanced reactor regulatory process through a variety of efforts. Some of these efforts are outlined in this section.

\subsubsection{SECY-18-0060, Achieving Modern Risk-Informed Regulation}

In SECY-18-0060, ${ }^{19}$ the staff recommends that the Commission approve several significant and specific revisions to the regulatory framework and approaches to better enable the safe and secure use of new technologies. Specifically, the staff recommends that the Commission do the following.

- Enable the staff to scale the scope of review and the level of detail needed in licensing to make a finding of reasonable assurance of adequate protection of public health and safety.

o Expand the use of qualitative and quantitative risk insights to scale the scope and depth of licensing reviews, depending on the safety and security significance of the matter being reviewed.

o Balance any new technology uncertainty with the expected safety benefit.

o Expand the ability to leverage existing internal and external information such as operating experience, third-party approvals, and the use of consensus standards.

o Use organizational tools to facilitate timely decision making.

- Develop a performance-based, technology-inclusive regulation as an alternative approach for licensing for non-LWRs. 
- Develop a new regulation to define high-level performance-based I\&C safety design principles and associated regulatory guidance that documents the acceptable standards that may be used to meet these principles.

\subsubsection{Draft Guidance to Implement the LMP}

NRC staff are working on draft guide (DG)-1353, Guidance for a Technology-Inclusive, Risk-Informed, Performance-Based Approach to Inform the Content of Applications for Licenses, Certifications, and Approvals for Non-Light Water Reactors. This guidance will provide an optional process for advanced non-LWR vendors to select technology-inclusive, risk-informed, and performance-based LBEs. Within the guidance, the selection of suitable LBEs leads to selection of appropriate safety classification of SSC and the adequacy of defense-in-depth measures for the advanced reactor design. The methodology is intended to lead to a finding of reasonable assurance of adequate radiological protection for the reactor design.

\subsubsection{NEI Proposed Physical Security Requirements for Advanced Reactors}

NEI prepared a December 2016 white paper discussing the potential for updated security requirements for advanced reactors. The industry basis for change is that advanced reactor designs are being proposed that can prevent radiological sabotage primarily through engineered safety and security features. NEI subsequently contends that it is reasonable to consider new physical security requirements for advanced reactor technologies because their enhanced safety and security features will make the accomplishment of radiological sabotage extremely unlikely. New physical security regulations that are aligned with the inherently lower risk profile of advanced reactor technologies should be established in advance of a design- or site-specific application that ultimately maintain the same public protection standards.

The rule changes proposed by NEI promote the establishment of a clear, predictable, and stable licensing process for advanced reactor technologies and avoid the inefficiency and uncertainty associated with achieving compliance through alternative measures, exemptions, and license conditions. Specific performance capabilities would need to be met that consider the likelihood of sabotage that can lead to unmitigated core damage or spent fuel damage.

NRC staff responded to the NEI security proposal with a November 2017 draft white paper on security (ML17333A524). The paper notes that the need for physical security is based upon the potential ability of would-be adversaries to cause a release of radioactive materials by acts of radiological sabotage or removing special nuclear material from the facility by theft or diversion. The current physical security framework for large LWRs is designed to address the possibility of an adversary force disabling particular target sets of SSC, resulting in a loss of safety functions leading to damage of a reactor core or spent fuel and a release of radioactive materials. Therefore, the staff concurred that designs and behavior of SMRs and non-LWRs can be significantly different from large LWRs and may warrant different physical security requirements. In August 2018, the staff issued SECY-18-0076 (ML18052B032) ${ }^{20}$ on physical security for advanced reactors.

\subsubsection{Proposed Rulemaking on Emergency Planning}

SMRs and certain advanced non-LWRs will have smaller cores and better cooling margins than current large LWRs. This will lead to a smaller source term for these reactors. NRC staff is working on a proposed rulemaking that will allow an alternate method for determining the plume exposure pathway emergency planning zone (EPZ). The alternate method will provide a technology-inclusive, riskinformed, performance-based approach using the principle of dose-at-distance and consequence to determine the appropriate EPZ size. This may lead to a reasonable assurance determination of an onsite 
EPZ or an offsite EPZ that is smaller than the traditional EPZ. The performance-based aspects of the rule may include

- event mitigation,

- $\quad$ protective actions,

- communications,

- command and control,

- staffing, and

- radiological assessment.

DG-1350 on emergency preparedness and the proposed rulemaking are expected in early 2019. The traditional EPZ methodology will remain as an option for advanced reactors and the only option for existing nuclear power plants.

\subsubsection{NRC Vision and Interim Action Plan}

NRC staff is aware of the number and variety of potential advanced reactor vendors working on advanced non-LWR designs. The staff prepared a vision and strategy document ${ }^{21}$ and an associated near-term implementation action plan ${ }^{22}$ to support the eventual review and regulation of a new generation of nonLWRs. The strategy notes that the agency needs to be effective and efficient as it conducts its safety, security, and environmental protection mission, without imposing unnecessary regulatory burden. This includes licensing reviews associated with fuel fabrication, storage, transportation, and disposal and requires the NRC to consider the effects of a more dynamic domestic regulatory environment and a globalized non-LWR industry. Furthermore, the NRC recognizes the benefits of having a flexible regulatory framework, allowing potential applicants to select a best-fit path towards regulatory reviews and decisions.

The near-term implementation action plan provides a planning tool that describes (1) what work must be done to achieve non-LWR readiness, (2) how the work should be sequenced, (3) how to prepare the workforce to do the work, and (4) considerations for organizing work execution for maximum effectiveness and efficiency.

\subsection{TOPICAL AREAS FOR DEVELOPMENT}

Many licensing tasks intended to identify MSR R\&D efforts are listed in the body of the roadmap. These tasks are listed in the following broad topical areas. All items in the list support reactor licensing. DOE should work with NRC to address the distinctive technological challenges related to MSR licensing.

- Qualification of molten salt fuel and fuel cycle

- Qualification of clad structural alloys, which is challenging for complex structures such as heat exchangers

- Development and demonstration of reactor materials

- Development of codes and standards for high-temperature materials

- $\quad$ Need to understand the life cycles of radioactive materials in the systems

- Develop ability to track actinides for safeguards purposes

- Identification of MSR accidents 
- Development of sensors and diagnostic tools to provide for reactor protection

- Identification of the source terms important to safety analysis

- Need to understand the physical behaviors of source-term elements

- Demonstration of passive decay heat removal systems

- Identification of MSR licensing basis events, estimates of event frequencies and uncertainties, classification of SSC, and analyses of defense-in-depth

- Demonstration of safety-related systems and components

- Analysis of the need for electric power

- Need to understand properties and handling processes for chloride-based salts and to extend fluoride-salt chemistry baseline information that will also aid in further understanding of chloride salts

- Development and demonstration of technology options for sequestering tritium produced in MSRs that use lithium salts

- Development of functional containment requirements including fission product barriers

- Development and demonstration of shielding techniques

- Analysis of below-grade siting

- Refinement of applicable physics codes, radiation transport codes, and thermal-hydraulics codes for MSRs

- Development of predictive modeling and simulation tools to ensure safe designs for efficient reactor performance and reduce the number of necessary experiments or tests

- Development of currently immature technologies to perform maintenance and component replacement in the highly radioactive near-core environment.

\subsection{SUMMARY OF SPECIFIC TASKS IDENTIFIED IN THE ROADMAP TEXT}

Numerous licensing tasks supported by MSR R\&D are included in the roadmap. These tasks are collected here for reference. An estimation of the task priority is provided with each task:

1 - implies an immediate or very near-term task;

2 - implies an intermediate-term task or next 2-5 years; and

3 - implies a long-term task.

In addition to priority, an estimation of programmatic involvement is included, such as lab directed, Nuclear Energy University Program (NEUP), or Small Business Initiative (SBI). Table 1 (on page 52) summarizes the proposed task priorities at the end of this section.

\section{Licensing Basis Event Selection}

Task 3.1.1 - LBE Selection for Salt-fueled MSRs: No specific MSR design is advocated by this roadmap. However, it is important that an appropriate set of basic salt-fueled MSR LBEs be developed. An expert panel should be convened to define MSR generic sets of accidents beginning with a master logic diagram to focus efforts. The expert panel should consider the LMP process, the brief operating history of salt-fueled MSRs, and expert judgment. This effort should support development of ANS 20.2, "Nuclear Safety Design Criteria and Functional Performance Requirements for Liquid-Fuel Molten-Salt 
Reactor Nuclear Power Plants.” This task will subsequently support the development of accidentinitiating events and accident sequences. This task will then directly support the development of saltfueled MSR accident analysis codes. This approach is necessary because there is no publicly available salt-fueled MSR design with an established PRA.

[Priority - 1, Lab directed]

Task 3.1.2 - LBE Selection for FHRs: No specific FHR design is advocated by this roadmap. However, it is important that an appropriate set of FHR LBEs be developed. An expert panel should be convened to define FHR generic sets of accidents beginning with a master logic diagram to focus efforts. Because the FHR has characteristics of both liquid-metal reactors and high-temperature gas reactors, this effort can draw on the experience already gained in evaluating those technologies. A recent study examined initiating events for these two reactor classes. ${ }^{7}$ This study should be expanded to include FHRs. This effort should support development of ANS 20.1, "Nuclear Safety Criteria and Design Process for Fluoride Salt-Cooled High-Temperature Reactor Nuclear Power Plants.” This task will subsequently support the development of FHR accident sequences and will then directly support the development of FHR accident analysis codes.

[Priority - 2, Lab directed]

\section{Use of Probabilistic Risk Assessment}

Task 3.2.1 - Determine Event Frequency and Uncertainty: Estimates of the salt-fueled MSR and FHR event frequencies will need to be generated for the initiating events. Appropriate treatment of uncertainties will need to be emphasized. This will directly support the iterative evaluation of the safety classification of generic SSC (Tasks 3.3.1 and 3.3.2). This task follows Tasks 3.1.1 and 3.1.2. The task will drive R\&D requirements for SSC, support accident analysis, and support defense-in-depth considerations.

[Priority - 1, NEUP, Labs]

\section{Classification of Structures, Systems, and Components}

Task 3.3.1 - SSC Classification: Categorize safety-related salt-fueled MSR and FHR SSC. The safety classification determines the level of scrutiny applied to these SSC over the lifetime of the reactor and defines their failure thresholds. The safety classification of SSC will be determined by a combination of deterministic and probabilistic methods. This task follows Task 3.2.1. This task will drive R\&D requirements for SSC, support accident analysis, and support defense-in-depth considerations.

[Priority - 2, Lab directed]

\section{Defense-In-Depth}

Task 3.4.1 - Determine Defense-In-Depth Systems: Categorize defense-in-depth salt-fueled MSR and FHR SSC. Based on the results on Task 3.3.1, identify defense-in-depth SSC that may require special regulatory treatment because of their function to supplement the safety-related SSC in mitigating AOOs, DBAs, and BDBAs. For example, current LWRs use barriers for defense-in-depth to protect the public health and safety - fuel, cladding, reactor vessel, and containment. A risk-informed defense-in-depth approach for MSRs may use different metrics to select defense-in-depth SSC.

[Priority - 2, Lab directed]

\section{Regulatory Guidance}

Task 3.5.1 - MSR Guidance Document Support: In addition to the near-term LMP effort, DOE should provide longer-term specific support of MSR licensing review documents. Essentially, this is the root structure for the licensing tree depicted in Figure 2. The policy, regulations, and guidance for unique 
technologies need to evolve such that an eventual MSR application will move efficiently through the licensing process. Licensing evaluations for commercial MSRs are anticipated to be like those for other advanced reactor concepts, the details of which are not fully developed. An evaluation of Regulatory Guide (RG) $1.206^{8}$ and NUREG 0800, Chapter 4, "Reactor," Chapter 5, "Reactor Coolant System and Connected Systems," Chapter 6, "Engineered Safety Features,” and Chapter 9, “Auxiliary Systems” (includes gas system, filters, and fission product traps), should be considered for MSR technologies. These NUREG 0800 chapters will likely be the most impacted by MSR technology and should be evaluated to determine changes needed for better applicability to MSRs. Generic MSR licensing issues deemed important to a wide population of potential applicants will generally receive NRC staff feedback at no cost. Support for licensing issues related to a specific MSR design concept can subsequently be considered separately and in a manner that properly protects intellectual property.

[Priority - 3, Lab directed]

Task 3.5.2 - Review of Supporting and Guidance Documents: As a trickle-down task from Task 3.5.1, all supporting documentation identified by Task 3.5.1 should be reviewed for applicability to MSR technology. DOE should suggest approaches to make these supporting documents (RGs, NUREGs, etc.) more performance based with respect to MSR technology. This will facilitate future technology-specific interactions between individual vendors/applicants and NRC staff. Otherwise, technology advances, experimental results, and data acquisition may be hampered by an ill-equipped review process.

Further effort will be needed to generate a preliminary licensing strategy for a demonstration or test reactor, which will likely require NRC staff development and use of an MSR version of NUREG-1537. ${ }^{9}$ A separate NUREG-1537 effort led by Southern Company and TerraPower under a cost-share agreement with DOE, and supported by NEI, is currently under way. A DOE-sponsored proposal for an update to NUREG-1537 for salt-fueled MSRs was recently released. ${ }^{23}$ FHRs should be able to be reviewed using the existing guidance.

[Priority - 3, Lab directed]

\section{Demonstration of Liquid Fuel Performance}

Task 4.1.1 - Salt-fueled MSR Fuel Qualification: Research is necessary to support the development of a salt-fueled MSR fuel qualification plan for the entire fuel cycle. Fuel qualification is a significant branch on the licensing tree depicted in Figure 2. Facets of the plan will include the following.

1. Fabrication
a. Flush salt
b. Fuel salt
c. Coolant salt

2. Packaging

3. Transportation

4. Storage

5. Unpacking

6. Fuel makeup
a. Chemistry
b. Technical Specifications

7. Normal operation and AOOs

8. Accidents 
9. Source terms

10. Fission product transport

11. Used fuel processing

12. Used fuel storage

13. Used fuel transportation

[Priority - 1, Lab directed]

\section{Codes for Physics and Thermal Fluids}

Task 5.1.1 - Develop Salt-fueled MSR Codes: Core heat removal is a significant branch in the licensing tree depicted in Figure 2. Development of an analytical capability for an MSR will likely require coupling between a thermal-fluids code and a neutronics code to simultaneously simulate the power, temperature, and velocity profile within the fuel/coolant mixture. The effort related to TRACE will be supported by NRC, but support for other codes will likely need to come from DOE. A gap analysis needs to be performed to determine the codes that are applicable to salt-fueled MSRs, determine required changes in existing codes, and identify new codes that address the unique features of an MSR. This will support modeling and simulation of salt-fueled MSR normal and accident conditions.

[Priority - 1, NEUP, Labs]

Task 5.1.2 - Develop FHR Codes: Because an FHR uses solid fuel, many existing codes may be applicable. However, with heat transfer to a molten salt, a gap analysis needs to be performed to determine the codes that are applicable to FHRs, determine required changes in existing codes, and identify new codes that address the unique features of an FHR. This will support modeling and simulation of FHR normal and accident conditions.

[Priority - 2, NEUP, Labs]

\section{Heat Removal System Testing}

Task 5.2.1 - MSR System Tests: To support the heat removal R\&D needs listed in Section 5.2, numerous test loops should be developed, including the following.

Forced-flow test loops: Life cycle behavior of fission products and other isotopes produced during operation depends on flow conditions within the reactor. Loops are needed to generate representative salt flow velocities at the temperatures of interest while in contact with candidate structural materials.

Initially, these loops will be laboratory-scale experiments, but they will later evolve to engineering-scale demonstrations.

Component test loops: The manufacturing sector must be motivated to participate in the production of reactor components with the material combinations needed for MSRs. A program to encourage industry participation in the development of a non-nuclear salt test facility to test the components is needed. Because salt-to-salt heat exchangers are important to MSR deployment, eventually a two-loop salt test bed will be necessary. Two-loop systems allow for simultaneous testing of similar technologies (i.e., pumps) in separate test environments (primary and intermediate heat transfer systems).

Loops will provide data for use in models to design the next generation of more complex loops. Data from the new loops will validate performance of the models used to predict their behavior. Over the course of an iterative build-and-test activity, the necessary tools will be produced to evaluate candidate reactor concepts for licensing, along with the evidence necessary to justify their use. The tools and the experts using them must mature along with the experimental program.

[Priority - 1, NEUP, SBI, Labs] 


\section{Codes and Standards Development}

Task 6.2.1 - MSR Codes and Standards Development: A gap analysis needs to be performed to determine the codes and standards that are applicable to MSRs, determine required changes in existing codes and standards, and identify new codes and standards that address the unique features of an MSR. This will help focus material R\&D on appropriate MSR applications. In addition, codes and standards for advanced reactor are being discussed in several venues. DOE should ensure that MSR technology is supported in all venues to evaluate stakeholder priorities. DOE should advocate for MSR codes and standards and interact with the NRC in this process to incorporate voluntary consensus codes and standards into their regulations. This will simplify and expedite regulatory review for future applications.

[Priority - 1, Lab directed]

\section{Develop Required Methods and Data}

Task 7.1.1 - Develop MSR Performance Models: A licensing challenge (Figure 2) for MSR development is the development of integrated performance models that can be used for reactor concept performance validation and licensing. To meet this challenge, the following capabilities are needed for each concept under consideration.

1. Identification of startup core salt compositions

2. Core neutronic evaluation, including precursor drift models that account for delayed neutron production throughout the primary loop and their reintroduction into the core

3. Radionuclide inventory accounting, including source term production, holdup and release mechanism models for specific materials and operating conditions, and appropriate salt solubility and thermo-physical property models

4. Thermal-hydraulic analyses of sufficient fidelity to capture flow and power dynamics in saltfueled concepts, including the use of computational fluid dynamics codes to evaluate open core concepts

5. Time-, temperature-, flux-, and flow-dependent materials and salt interaction data and models to predict corrosion, erosion, and irradiation effects

6. Dynamic reactor system models that include primary system isotope transport and constituent holdup and release mechanisms

This task is related to Tasks 5.1.1 and 5.1.2.

[Priority - 2, NEUP, Labs]

\section{Validate Codes and Models}

Task 7.2.1 - MSR Code Validation: Validating computer codes for MSR applications remains important and involves code validation and experimental work to generate validation data needed for code development and qualification activities. DOE should support development of a detailed modeling roadmap to identify long-term modeling and simulation needs and the near-term R\&D activities to meet them.

[Priority - 1, NEUP, Labs]

\section{Sensors and Controls}

Task 8.1.1 - MSR Sensors and Controls: Research should be conducted on sensors and controls that can withstand the severe environments encountered in MSR designs as identified by industry and necessary to support the plant licensing basis. Safety-related instrumentation should be simplified to the 
extent possible to provide the highest possible assurance of reliable, safe operation while minimizing equipment qualification challenges.

[Priority - 1, SBI, NEUP, Labs]

\section{Surveillance and Diagnostics}

Task 8.2.1 - MSR Surveillance and Diagnostics: Analyses should be conducted to identify technology gaps related to loose part monitoring, sampling procedures, small sample tubing, flanges, and leak detection. This will directly support R\&D associated with these specific diagnostic issues. This ultimately will support the establishment of Technical Specifications related to sampling and leakage detection.

[Priority - 2, Lab directed]

\section{Human Factors}

Task 8.3.1 - MSR Human Factors: A gap analysis needs to be performed on MSR communication requirements, man-machine interface requirements, and autonomous control requirements. Investigate the need for remote operations to conduct surveillances and equipment maintenance.

[Priority - 3, Lab directed]

\section{$\underline{\text { Structural Tests }}$}

Task 9.1.1 - MSR Loop Tests: A conceptual progression of single-purpose loops evolving to reactorscale component testing for the study of fabrication methods, chemistry, and structural integrity under relevant operating conditions includes the following.

1. Develop the capability to produce, process (clean), and characterize salts.

2. Establish natural circulation harp loops at representative temperatures using a variety of salt and structural material combinations.

3. Create forced-flow (pumped) loops to create representative flow and temperature conditions.

4. Develop larger separate-effects loops to study specific MSR issues and to test mitigating strategies for issues such as tritium production and fission product life cycle.

5. Conduct an engineering scale demonstration of components and system operation and management.

6. Conduct reactor-scale component loop testing.

[Priority - 1, NEUP, Labs]

\section{Remote Operations}

Task 9.2.1 - Salt-fueled MSR Remote Maintenance: Analyses should be conducted to determine best practices for remote maintenance, inspection, and recovery operations to support the ability to meet Technical Specifications and operations programs. Such analyses could lead to R\&D for maintenance and inspection mockups using long-handled tools, digital tools, and other remote inspection technologies. This task is related to Task 8.3.1.

[Priority - 3, Lab directed]

\section{$\underline{\text { Safeguards }}$}

Task 10.1.1 - Salt-fueled MSR Safeguards Assessment: A generic MSR safeguards needs assessment should be performed to describe typical safeguards objectives and methodologies, identify probable key 
measurement points and control areas within proposed designs, and describe the possible monitoring methods. This information will be used to identify gaps between anticipated needs and current measurement. This will further identify needed R\&D to provide adequate safeguards monitoring capabilities.

Subsequently, design variants will require specific evaluation due to differences in salt process flows, salt fueling methods, salt cleanup technologies employed, the export control status of required technologies, and the deployment intent (i.e., domestic and/or international). Results of the needs assessment should explicitly consider and discuss reprocessing requirements and deployment strategies, as well as expectations for final waste forms and disposition strategies.

[Priority - 1, Lab directed]

\section{Fission Products}

Task 10.2.1 - Salt-fueled MSR Fission Product Analysis: Analyses into the development of radiation protection design features should be conducted based on fission product transport, disposition (plate-out), cleanup, and polishing. This directly supports the analysis of source terms.

[Priority - 2, Lab directed]

\section{Salt Science}

Task 10.3.1 - MSR Salt Evaluations: Out-of-pile and in-pile tests for fluoride and chloride salts should be conducted. The purpose is to collect data on corrosion rates and proposed reactor materials to support understanding of salt corrosion mechanisms. The performance of the selected redox control method needs to be demonstrated in electrically heated salt loops to provide confidence that the protection system will perform as anticipated. Information on salt stability should also be documented. This directly supports material R\&D and barrier analyses.

[Priority - 2, Lab directed]

\section{Containment}

Task 10.4.1 - Develop Functional Containment Requirements for Salt-fueled MSRs: The analyses and code considerations necessary for MSRs to employ a functional containment process should be investigated. This will support materials $R \& D$ for the various functional containment barriers as well as source term evaluations and siting considerations.

[Priority - 1, NEUP, Labs]

Task 10.4.2 - Develop Storage Requirements for Salt-fueled MSR Components: Salt-fueled MSR components will become highly radioactive after reactor operation. An analysis of the storage requirements for replaced or residual parts should conducted. This will support materials R\&D and component maintenance R\&D.

[Priority - 3, NEUP, Labs]

Task 10.4.3 - Attributes of MSR Underground Siting: Many advanced reactors are considering a reactor building that is completely or partially below grade. A topical report should be prepared on the attributes of underground siting. This would include such considerations as seismic advantage, sourceterm retention, aircraft hazards, fire and flooding, security, control, and staff ingress and egress. Belowgrade siting is often touted as a licensing advantage, but no reference documentation exists. This would directly support materials R\&D, seismic R\&D, fission product transport, DBA modeling and simulation, and siting.

[Priority - 1, Lab directed] 


\section{Mechanistic Source Term}

Task 11.1 - MSR Mechanistic Source-Term Evaluation: To address the licensing questions related to source term, analyses addressing the key phenomenology associated with major MSR variants must be performed to identify generic MSR, and eventually design-specific accident event sequences.

Radionuclide retention in molten salt needs to be evaluated. Information that must be identified to perform accurate accident analyses includes the following:

- salt properties under worst-case scenarios,

- radioactive inventories within a system,

- holdup and release mechanism models for radioactive source terms, and

- technologies available to mitigate and manage radioactive material releases including engineered safety features.

[Priority - 2, Lab directed]

Table 1. Task Priority Table

\begin{tabular}{|c|c|c|c|c|c|c|c|}
\hline \multirow[t]{2}{*}{ Task } & \multicolumn{3}{|c|}{ Priority } & \multicolumn{4}{|l|}{ Entity } \\
\hline & 1 & 2 & 3 & Lab directed & Lab involvement & NEUP & SBI \\
\hline \multicolumn{8}{|c|}{ Licensing Basis Event Selection } \\
\hline 3.1 .1 & $\mathrm{X}$ & & & $X$ & & & \\
\hline 3.1 .2 & & $\mathrm{X}$ & & $\mathrm{X}$ & & & \\
\hline \multicolumn{8}{|l|}{ Use of PRA } \\
\hline 3.2 .1 & $\mathrm{X}$ & & & & $\mathrm{X}$ & $X$ & \\
\hline \multicolumn{8}{|l|}{ Classification of SSC } \\
\hline 3.3 .1 & & $\mathrm{X}$ & & $\mathrm{X}$ & & & \\
\hline \multicolumn{8}{|l|}{ Defense-In-Depth } \\
\hline 3.4 .1 & & $\mathrm{X}$ & & $\mathrm{X}$ & & & \\
\hline \multicolumn{8}{|l|}{ Regulatory Guidance } \\
\hline 3.5 .1 & & & $\mathrm{X}$ & $\mathrm{X}$ & & & \\
\hline 3.5 .2 & & & $\mathrm{X}$ & $\mathrm{X}$ & & & \\
\hline \multicolumn{8}{|l|}{$\begin{array}{l}\text { Demonstration of Liquid Fuel } \\
\text { Performance }\end{array}$} \\
\hline 4.1 .1 & $\mathrm{X}$ & & & $\mathrm{X}$ & & & \\
\hline \multicolumn{8}{|c|}{$\begin{array}{l}\text { Codes for Physics and Thermal } \\
\text { Fluids }\end{array}$} \\
\hline 5.1 .1 & $\mathrm{X}$ & & & & $\mathrm{X}$ & $\mathrm{X}$ & \\
\hline 5.1 .2 & & $\mathrm{X}$ & & & $\mathrm{X}$ & $\mathrm{X}$ & \\
\hline \multicolumn{8}{|c|}{$\begin{array}{l}\text { Codes for Physics and Thermal } \\
\text { Fluids }\end{array}$} \\
\hline 5.2 .1 & $\mathrm{X}$ & & & & $\mathrm{X}$ & $\mathrm{X}$ & $\mathrm{X}$ \\
\hline \multicolumn{8}{|l|}{$\begin{array}{l}\text { Codes and Standards } \\
\text { Development }\end{array}$} \\
\hline 6.2 .1 & $\mathrm{X}$ & & & $\mathrm{X}$ & & & \\
\hline \multicolumn{8}{|c|}{$\begin{array}{l}\text { Develop Required Methods and } \\
\text { Data }\end{array}$} \\
\hline 7.1 .1 & & $\mathrm{X}$ & & & $\mathrm{X}$ & $\mathrm{X}$ & \\
\hline Validate Codes and Models & & & & & & & \\
\hline
\end{tabular}




\begin{tabular}{|c|c|c|c|c|c|c|c|}
\hline \multirow[t]{2}{*}{ Task } & \multicolumn{3}{|c|}{ Priority } & \multicolumn{4}{|l|}{ Entity } \\
\hline & 1 & 2 & 3 & Lab directed & Lab involvement & NEUP & SBI \\
\hline 7.2 .1 & $\mathrm{X}$ & & & & $\mathrm{X}$ & $\mathrm{X}$ & \\
\hline Sensors and Controls & & & & & & & \\
\hline 8.1 .1 & $\mathrm{X}$ & & & & $\mathrm{X}$ & $\mathrm{X}$ & $\mathrm{X}$ \\
\hline Surveillance and Diagnost & & & & & & & \\
\hline 8.2 .1 & & $\mathrm{X}$ & & $\mathrm{X}$ & & & \\
\hline Human Factors & & & & & & & \\
\hline 8.3 .1 & & & $\mathrm{X}$ & $\mathrm{X}$ & & & \\
\hline Structural Tests & & & & & & & \\
\hline 9.1 .1 & $\mathrm{X}$ & & & & $\mathrm{X}$ & $\mathrm{X}$ & \\
\hline Remote Operations & & & & & & & \\
\hline 9.2 .1 & & & $\mathrm{X}$ & $\mathrm{X}$ & & & \\
\hline Safeguards & & & & & & & \\
\hline 10.1 .1 & $\mathrm{X}$ & & & $\mathrm{X}$ & & & \\
\hline Fission Products & & & & & & & \\
\hline 10.2 .1 & & $\mathrm{X}$ & & $\mathrm{X}$ & & & \\
\hline Salt Science & & & & & & & \\
\hline 10.3 .1 & & $\mathrm{X}$ & & $\mathrm{X}$ & & & \\
\hline Containment & & & & & & & \\
\hline 10.4 .1 & $\mathrm{X}$ & & & & $\mathrm{X}$ & $\mathrm{X}$ & \\
\hline 10.4 .2 & & & $\mathrm{X}$ & & $\mathrm{X}$ & $\mathrm{X}$ & \\
\hline 10.4 .3 & $\mathrm{X}$ & & & $\mathrm{X}$ & & & \\
\hline Mechanistic Source Term & & & & & & & \\
\hline 11.1 & & $\mathrm{X}$ & & $\mathrm{X}$ & & & \\
\hline
\end{tabular}




\section{REFERENCES}

1. A Regulatory Review Roadmap for Non-Light Water Reactors, NRC, ML17312B567, December 2017.

2. “Policy Statement on the Regulation of Advanced Reactors," NRC, 73 FR 60612, October 14, 2008.

3. NRC Non-Light Water Reactor Near-Term Implementation Action Plans, ML17165A069, July 2017.

4. NRC Non-Light Water Reactor Mid-Term and Long-Term Implementation Action Plans, ML17164A173, July 2017.

5. NRC, Standard Review Plan for the Review of Safety Analysis Reports for Nuclear Power Plants: LWR Edition, NUREG-0800, March 2007.

6. Southern Company, Modernization of Technical Requirements for Licensing of Advanced Non-Light Water Reactors, Risk-Informed Performance-Based Guidance for Non-Light Water Reactor Licensing Basis Development, Revision M, May 27, 2018.

7. M. D. Muhlheim, Identification of Initiating Events for aSMRs, ORNL/TM-2013/513, ORNL, Oak Ridge, TN, June 2013.

8. NRC, “Combined License Applications for Nuclear Power Plants,” RG 1.206, June 2007.

9. NRC, “Guidelines for Preparing and Reviewing Applications for the Licensing of Non-Power Reactors,” NUREG-1537, October 2012.

10. R. J. Belles, G. F. Flanagan, M. Voth, Proposed Guidance for Preparing and Reviewing Molten Salt Nonpower Reactor License Applications, ORNL/TM-2018/834, ORNL, Oak Ridge, TN, May 2018.

11. Technical Program Plan for the Next Generation Nuclear Plant/Advanced Gas Reactor Fuel Development and Qualification Program, PLN-3636, INL, Idaho Falls, ID, September 2010.

12. Evaluation of MHTGR Fuel Reliability-Chapter 6 LWR Fuel Reliability Perspective, NUREG/CR5810 and ORNL/TM-12014, NRC, Washington, DC, and ORNL, Oak Ridge, TN.

13. R. N. Wright and T. L. Sham, Status of Metallic Structural Materials for Molten Salt Reactors, INL/EXT-18-45171, INL, Idaho Falls, ID, May 2018.

14. D. Diamond et al., Phenomena Identification and Ranking Tables (PIRTs) Report for Material Selection and Possible Material Degradation Mechanisms in FHR, Georgia Institute of Technology, 2017.

15. D. E. Holcomb, et. al., Instrumentation Framework for Molten Salt Reactors, ORNL/TM-2018/868, ORNL, Oak Ridge, TN, June 2018.

16. Draft White Paper, “Functional Containment” Performance Criteria November 2017 Draft - Released to Support Public Discussions.”

17. NRC, "Policy Statement on the Regulation of Advanced Reactors," NRC-2008-0237.

18. P. N. Haubenreich and J. R. Engel, Safety Calculations for MSRE, ORNL-TM-251, May 1962.

19. NRC, “Achieving Modern Risk-Informed Regulation,” SECY 18-0060, May 23, 2018.

20. NRC, “Options and Recommendation for Physical Security for Advanced Reactors,” SECY 18-0076, August 1, 2018.

21. NRC Vision and Strategy: Safely Achieving Effective and Efficient Non-Light Water Reactor Mission Readiness, 2016, ML16356A670. 
22. NRC Non-Light Water Reactor (Non-LWR) Vision and Strategy - Staff Report: Near-Term Implementation Action Plans, Volume 1 and Volume 2, 2016, ML16294A181 and ML16334A495.

23. R. J. Belles, G. F. Flanagan, M. Voth, Proposed Guidance for Preparing and Reviewing Molten Salt Nonpower Reactor License Applications, ORNL/TM-2018/834, ORNL, Oak Ridge, TN, May 2018. 